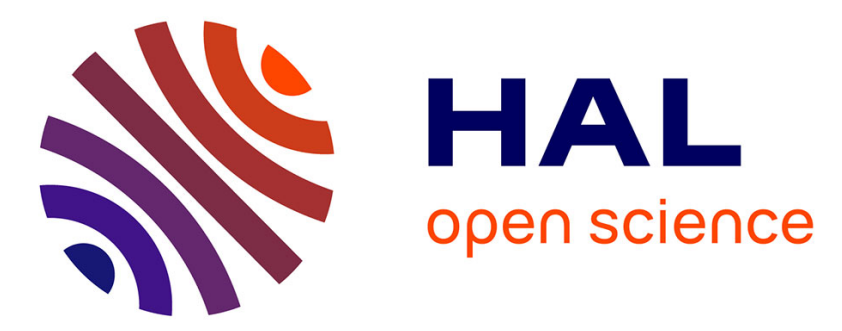

\title{
Cholecalciferol (Vitamin D3) Reduces Rat Neuropathic Pain by Modulating Opioid Signaling
}

Pierrick Poisbeau, Maya Aouad, Géraldine Gazzo, Adrien Lacaud, Véronique Kemmel, Véréna Landel, Vincent Lelièvre, François Feron

\section{To cite this version:}

Pierrick Poisbeau, Maya Aouad, Géraldine Gazzo, Adrien Lacaud, Véronique Kemmel, et al.. Cholecalciferol (Vitamin D3) Reduces Rat Neuropathic Pain by Modulating Opioid Signaling. Molecular Neurobiology, 2019, 56 (10), pp.7208-7221. 10.1007/s12035-019-1582-6 . hal-02282087

\section{HAL Id: hal-02282087 \\ https://hal-amu.archives-ouvertes.fr/hal-02282087}

Submitted on 3 Mar 2020

HAL is a multi-disciplinary open access archive for the deposit and dissemination of scientific research documents, whether they are published or not. The documents may come from teaching and research institutions in France or abroad, or from public or private research centers.
L'archive ouverte pluridisciplinaire HAL, est destinée au dépôt et à la diffusion de documents scientifiques de niveau recherche, publiés ou non, émanant des établissements d'enseignement et de recherche français ou étrangers, des laboratoires publics ou privés. 


\section{Molecular Neurobiology \\ Cholecalciferol (vitamin D3) reduces rat neuropathic pain by modulating opioid signaling \\ --Manuscript Draft--}

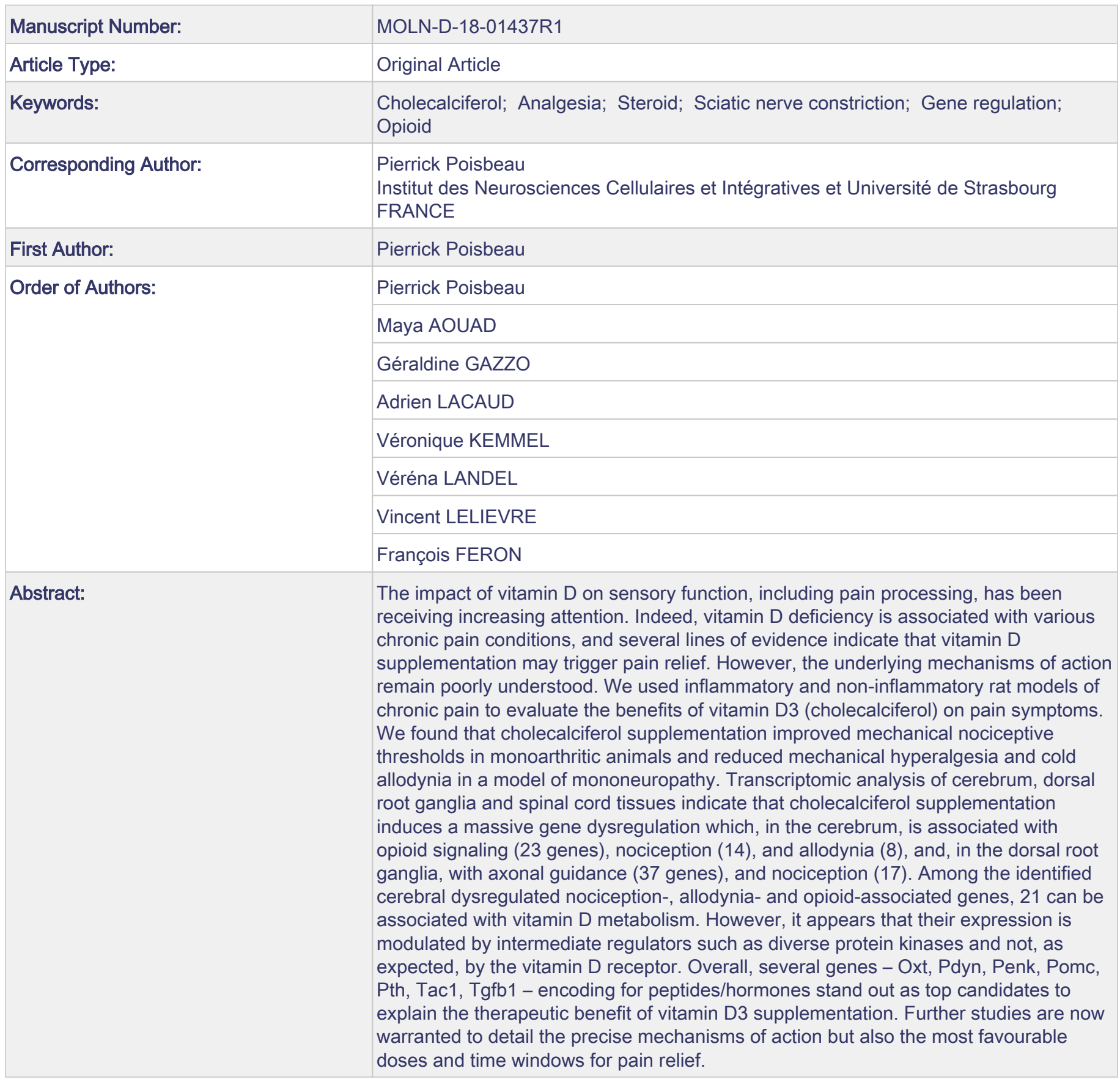




\section{Nicolas G. Bazan, Editor-In Chief}

Molecular Neurobiology

\section{Dear Editor,}

We hope this message finds you well and we thank you very much for your recent email. We are writing to you on behalf of all authors, with a special request for you to consider a revised version of our manuscript entitled "Cholecalciferol (vitamin D3) reduces rat neuropathic pain by modulating opioid signaling" by Poisbeau et al. for your consideration for publication as an article in Molecular Neurobiology.

We would like to thank the editor and reviewers for their comments and suggestions. We have been able to address all the raised concerns. Considering the requested changes, which were not experimental in nature, we are confident that we have addressed all the remaining concerns related to the main text. We thus hope that you will find the revised version of our manuscript suitable for publication in Molecular Neurobiology.

Yours sincerely,

Pierrick Poisbeau 


\section{Point-by-point response to the referees}

\section{Reviewer 1}

1. Please introduce (and consistently use) the nomenclature of vitamin D3 and its metabolite. Please do not confuse the reader by using two names for the same molecule. Moreover, please always write "vitamin D3" when you mean this molecule and not only "vitamin D", which some readers may interpret as "1,25(OH)2D3".

Response: We thank the reviewer for pointing out some potential misunderstandings, due to imprecise naming, and an insufficiently detailed biochemical pathway of vitamin D. When needed, the appropriate names for vitamin $D$ and its metabolites were inserted in the manuscript. In addition, we wrote a new section in the introduction chapter that now reads:

"Vitamin D is now recognized as an active and pleiotropic neurosteroid in the brain, where it acts as a hormone and a paracrine/autocrine agent [1; 2]. In mammals, vitamin D synthesis begins with cleavage of the B ring of 7-dehydrocholesterol, in the epidermis, under UVB radiation (290-315 $\mathrm{nm}$ ) producing an extremely unstable pre-vitamin D [3]. After spontaneous isomerization, this creates the precursor molecule, cholecalciferol, also commonly called vitamin D3, which is subjected to three further hydroxylations, two of which render it bioactive, the third one allowing for inactivation. The first hydroxylation step occurs under the activity of a number of microsomal cytochrome P450 enzymes. CYP27A1, CYP2J2 and CYP3A4 are potential players for the addition of a hydroxyl group on C25 of vitamin D, but CYP2R1 appears to be the most implicated enzyme in the conversion of cholecalciferol into 25 hydroxyvitamin D3 (25OHD3), or calcidiol (Cheng et al., 2003; Schuster, 2011). $25(\mathrm{OH}) \mathrm{D}$ is subsequently converted to 1,25 dihydroxyvitamin $\mathrm{D}(1,25(\mathrm{OH}) 2 \mathrm{D})$ or calcitriol, by another cytochrome P450 enzyme, CYP27B1 also referred to as 1 $\alpha$-hydroxylase. Once metabolized, 1,25(OH)D promptly upregulates the expression of a third cytochrome P450, CYP24A1, which catabolizes both 25(OH)D and 1,25OHD into biologically inactive, water soluble calcitroic acid (Holick, 2007). Within the whole body, calcitriol binds to the vitamin $D$ receptor (VDR) and induces the transcription of hundreds of genes."

2. A membrane receptor for vitamin $\mathrm{D}$ has not been formally characterized. Therefore, please do not confuse the reader about it and explain the observed effects via the only accepted vitamin D receptor, the nuclear receptor VDR.

Response: Nearly 50 peer-reviewed published articles describe the interactions between calcitriol and PDIA3 receptor. We also demonstrated that, when compared to VDR, PDIA3 transcripts are abundantly expressed in brain cells (Landel et al, 2018). However, in order to "not confuse the reader", we exclusively focused our introduction on VDR. The section mentioning the membrane receptor for vitamin $D$ was erased.

3. Oral vitamin D3 supplementation of $7,500 \mathrm{IU} / \mathrm{kg}$ is extreme, this would translate to some $500,000 \mathrm{IU}$ for humans. Are no effects observed at more moderate doses that reflect human supplementation habits? Also $3500 \mathrm{IU} / \mathrm{kg}$ by gavage is still out of range.

Response: We are sorry for possibly leading the reader on a wrong interpretation of our vitamin D3 supplementation. Each kilo of manufactured chow contained either 0 or 1,000 IU or 7,500 IU of vitamin D3. If we consider that a rat eats approximately $20 \mathrm{~g}$ of diet, every day, 
it means that the daily ingested dose of cholecalciferol is 0 or 20 IU or 150 IU. In a previous study, these kinds of doses were administered, for 3 months, to rats with a spinal cord injury and no adverse effect was observed (Gueye et al, 2015). However, to avoid any further confusion, we added a sentence in the Materials and Methods section which now reads:

"Vitamin D3 (cholecalciferol) was provided in the diet (monoarthritic model) or by gavage (monoarthritic and neuropathic models). Animals were fed with either a control diet (1,000 IU/kg), a vitamin D3-deficient diet (0 IU/kg) or a vitamin D3-supplemented diet (7,500 IU/kg) (INRA, France). If we consider that 300-350 g rats eat approximately 20 grams of chow, the administered doses of vitamin D3 were $60 \mathrm{IU} / \mathrm{kg} /$ day, $0 \mathrm{IU} / \mathrm{kg} /$ day and $450 \mathrm{IU} / \mathrm{kg} / \mathrm{day}$, respectively. Six weeks were required to reach the vitamin D-deficiency status. In parallel, a group of rats was vitamin D-supplemented by a weekly gavage (50,000 IU/ml, $200 \mu \mathrm{l} /$ week) (Uvedose, Crinex). Control animals received the same volume of triglycerides, the diluent for vitamin D3. Supplementation, through diet or gavage, was performed during 4 weeks."

4. It is unclear why in the year 2018 still microarrays are use and not RNA-seq. The advantages of the latter are obvious. Moreover, a link to the raw-data is missing. In addition, a meta-table with all microarray data would be essential, in order to follow the analysis procedure.

Response: As mentioned in our initial manuscript (section $M \& M$ ), all microarray data are available on the following website: ArrayExpress database (accession number E-MTAB6801).

We agree with the referee that the RNA-seq technique should be favored. However, when our study was performed, cDNA microarray technique was still recommended. In addition, we would like to mention that we recently performed a comparative study - microarray versus RNA-seq - on the same cell types. To our delight, the final results were strongly similar.

5. Ingenuity Pathway Analysis is outdated and replaced by more recent methods, please check "Enrichr".

Response: We are surprised to learn that IPA is outdated when so many published papers report its use for analysing -omics data. However, as recommended by the reviewer, we subjected our transcriptomic data to Enrichr. Undoubtedly, this software provides interesting information but failed to highlight nociception and allodynia pathways. As a result, we considered that the IPA-associated analysis should remain in the article.

6. The reference list is in part biased. It does not fully represent the modern state of the field and general findings in the filed of vitamin D are not mentioned while in part outdated older references are cited.

Response: We thank the reviewer for asking us to update our references. After checking all recent publications on vitamin $D$, inflammation, pain and nerve growth, we added $x$ publications:

- $\quad$ Sassi et al, 2018 
- Bivona et al, 2018

- Banafshe et al, 2018

- Yong et al, 2017

- de Oliveira et al, 2017

- Helde-Frankling and Björkhem-Bergman, 2017

We would be delighted if the reviewer can tell us whether other publications are missing.

Minor comments:

1. Was there really $300 \mu \mathrm{g}(=0.3 \mathrm{mg})$ RNA used for cDNA synthesis? This sounds far too much.

Response: We thank the reviewer for pointing out this mistake. The mass was 0.3 micrograms (and not $0.3 \mathrm{mg}$ ). It now appears in the text as $300 \mathrm{ng}$.

2. Please introduce every abbreviation at its first time use and apply it then consistently. This applies also to the Abstract, Figures and Tables.

Response: We have thoroughly checked our manuscript and figures/tables for abbreviations and have added the appropriate introduction for all abbreviations used.

3. Please double-check for the most-recent gene abbreviation nomenclature. Some gene names seem not to be correct or truncated.

Response: We thank the reviewer for pointing out our out-of-date gene nomenclature. We have checked gene abbreviation on the genecards.org website and have added under parenthesis the most recent nomenclature to clarify our text. This applies to Ac5 (Adcy5), Jnk (Mapk8), Erk1 (Mapk3), Erk2 (Mapk1) and P38mapk (Mapk14). We have decided to keep both nomenclatures in order to stay in accordance with the multiple figures of pathways we have generated.

\section{Reviewer \#2: This is a valuable study. It will be of interest to the readers of Molecular Neurobiology.}

Check thoroughly for grammatical errors; and image and figure legend legibility.

Response: We thank the reviewer for his/her positive comment. As recommended, we thoroughly checked the manuscript for grammatical errors, and increased the neatness of our images and the font of our legends. 


\title{
Cholecalciferol (vitamin D3) reduces rat neuropathic pain by modulating opioid signaling
}

\author{
Pierrick POISBEAU ${ }^{1 * \S}$, Maya AOUAD ${ }^{1 *}$, Géraldine GAZZO ${ }^{1}$, Adrien LACAUD ${ }^{1}$, Véronique \\ KEMMEL $^{2}$, Véréna LANDEL ${ }^{3}$, Vincent LELIEVRE ${ }^{1}$, François FERON ${ }^{3 \S}$,
}

\section{Affiliation :}

${ }^{1}$ Centre National de la Recherche Scientifique and University of Strasbourg, Institut des Neurosciences Cellulaires et Intégratives, Strasbourg, France.

${ }^{2}$ Centre Hospitalier Universitaire de Strasbourg, Faculté de Médecine, Laboratoire de Biochimie et Biologie Moléculaire, Strasbourg, France.

${ }^{3}$ Aix Marseille Université, CNRS, INP, Institut de Neurophysiopathologie, Marseille, France

* Equally contributed

Number of text pages : 31

Number of figures: 6

Supplementary material: 3 Figures and 2 Tables

$\S$ Corresponding authors:

Prof. Pierrick Poisbeau

Institut des Neurosciences Cellulaires et Intégratives, CNRS UPR 3212

5 rue Blaise Pascal, 67000 Strasbourg, France

Tel: (+33) 388456727

Email: poisbeau@inci-cnrs.unistra.fr

Prof. François Féron

Institut de NeuroPhysioPathologie, CNRS UMR 7051

Aix-Marseille Université - Faculté de Médecine Nord.

CS 811. 51 Bd P. Dramard. 13344 Marseille Cedex 15

Tél: (+33) 491698770

Email : francois.feron@univ-amu.fr 


\section{$\underline{\text { Abstract }}$}

The impact of vitamin D on sensory function, including pain processing, has been receiving increasing attention. Indeed, vitamin D deficiency is associated with various chronic pain conditions, and several lines of evidence indicate that vitamin D supplementation may trigger pain relief. However, the underlying mechanisms of action remain poorly understood. We used inflammatory and noninflammatory rat models of chronic pain to evaluate the benefits of vitamin D3 (cholecalciferol) on pain symptoms. We found that cholecalciferol supplementation improved mechanical nociceptive thresholds in monoarthritic animals and reduced mechanical hyperalgesia and cold allodynia in a model of mononeuropathy. Transcriptomic analysis of cerebrum, dorsal root ganglia and spinal cord tissues indicate that cholecalciferol supplementation induces a massive gene dysregulation which, in the cerebrum, is associated with opioid signaling (23 genes), nociception (14), and allodynia (8), and, in the dorsal root ganglia, with axonal guidance (37 genes), and nociception (17). Among the identified cerebral dysregulated nociception-, allodynia- and opioid-associated genes, 21 can be associated with vitamin D metabolism. However, it appears that their expression is modulated by intermediate regulators such as diverse protein kinases and not, as expected, by the vitamin D receptor. Overall, several genes - Oxt, Pdyn, Penk, Pomc, Pth, Tacl, Tgfbl - encoding for peptides/hormones stand out as top candidates to explain the therapeutic benefit of vitamin D3 supplementation. Further studies are now warranted to detail the precise mechanisms of action but also the most favourable doses and time windows for pain relief.

\section{$\underline{\text { Keywords }}$}

Cholecalciferol; Analgesia; Steroid; Sciatic nerve constriction; Gene regulation; Opioid 


\section{Introduction}

Vitamin D is now recognized as an active and pleiotropic neurosteroid in the brain, where it acts as a hormone and a paracrine/autocrine agent $[1 ; 2]$. In mammals, vitamin D synthesis begins with cleavage of the B ring of 7-dehydrocholesterol, in the epidermis, under UVB radiation (ultraviolet B; 290-315 $\mathrm{nm}$ ) producing an extremely unstable pre-vitamin D [3]. After spontaneous isomerization, this creates the precursor molecule, cholecalciferol, also commonly called vitamin D3, which is subjected to three further hydroxylations, two of which render it bioactive, the third one allowing for inactivation. The first hydroxylation step occurs under the activity of a number of microsomal cytochrome P450 enzymes. CYP27A1, CYP2J2 and CYP3A4 are potential players for the addition of a hydroxyl group on the $\mathrm{C} 25$ of vitamin D, but CYP2R1 appears to be the most implicated enzyme in the conversion of cholecalciferol into 25-hydroxyvitamin D3 [25(OH)D3], or calcidiol (Cheng et al., 2003; Schuster, 2011). 25(OH)D is subsequently converted to 1,25 -dihydroxyvitamin $\mathrm{D}\left[1,25(\mathrm{OH})_{2} \mathrm{D}\right]$ or calcitriol, by another cytochrome P450 enzyme, CYP27B1 also referred to as $1 \alpha$-hydroxylase. Once metabolized, $1,25(\mathrm{OH})_{2} \mathrm{D}$ promptly upregulates the expression of a third cytochrome P450, CYP24A1, which catabolizes both $25(\mathrm{OH}) \mathrm{D}$ and $1,25(\mathrm{OH})_{2} \mathrm{D}$ into biologically inactive, water soluble calcitroic acid (Holick, 2007). Within the whole body, calcitriol binds to the vitamin D receptor (VDR) and induces the transcription of hundreds of genes.

Evidence linking vitamin D and pain is based on in vitro, animal, epidemiological and clinical research. For instance, four observational studies report that hypovitaminosis D is associated with various forms of chronic pain [4-7]. Rats fed during 2-4 weeks with a vitamin D-deficient diet displayed mechanical deep muscle hypersensitivity [8]. Pain relief was also observed in vitamin Dtreated patients with fibromyalgia syndrome [9] or musculoskeletal complaints [10].

Although the published clinical studies are heterogeneous and sometimes of poor methodological quality, three meta-analyses of randomized, placebo-controlled trials were conducted [11-13]. They all conclude that there is modest level of evidence that vitamin D supplementation is efficient to treat chronic pain. In line, reviews of published randomized controlled trials report that vitamin D induces a 
significantly greater mean decrease in pain score for patients with chronic pain, compared with placebo [14-16], especially when patients display calcidiol [25(OH)D] levels below $30 \mathrm{nmol} / \mathrm{L}$ [17].

The basis for considering vitamin D as a potential pain killer stems partially from its well established role as a modulator of inflammatory and immune responses [18; 19]. In human lung fibroblasts, cholecalciferol, calcidiol and calcitriol inhibit the production of prostaglandin E2 (PGE2), a key factor in inflammatory pain [20], and its level of expression is reduced in patients with musculoskeletal pain treated with high doses of vitamin D3 [21]. However, since vitamin D supplementation could also be efficient in reducing symptoms in non-inflammatory chronic pain, other mechanisms may be at play [22].

Administration of vitamin D3 attenuated cold allodynia and heat hyperalgesia in a rat model of neuropathic pain, when delivery was started on the first day after surgery [23]. We also demonstrated that vitamin D3 supplementation improved functional recovery and myelination [24; 25]. Subsequently, we noticed a cholecalciferol-associated diminution of pain in humans with arm and/or hand nerve trauma (unpublished data). In order to assess whether cholecalciferol is a true painmodulator and identify its potential mechanisms of action, we performed the current study, based on two rat models of pain - knee monoarthritis and mononeuropathy - that represent good examples of chronic pain associated with various degrees of inflammation. Animals were supplemented with cholecalciferol for several weeks after which their nociceptive sensitivity to mechanical and cold stimuli was quantified. At the end of the experiment, the cerebrum, dorsal root ganglia (DRG) and spinal cord were collected and analyzed, by means of cDNA microarrays, quantitative PCR and bioinformatic tools, in order to identify the vitamin D-associated genes involved in nociception. 


\section{Methods}

\section{$\underline{\text { Animals and pain models }}$}

Male Sprague Dawley rats weighing 250-350 g (Janvier Le Genest St. Isle, France) were housed in groups of three, under standard conditions (room temperature: $22^{\circ} \mathrm{C} ; 12 / 12 \mathrm{~h}$ light-dark cycle) with $\mathrm{ad}$ libitum access to food and water. All experiments were conducted in conformity with the recommendations of the European Committee Council Direction of September 22, 2010 (2010/63/EU). Procedures were positively evaluated by the regional ethical committee and experiments were conducted with an official authorization for animal experimentation from the French Department of Agriculture (License 67-116 to PP).

Knee monoarthritis: Transient inflammation of the rat knee was induced by unilateral injection of $50 \mu \mathrm{L}$ CFA [complete Freund's adjuvant (Sigma St Louis, MO, USA)] under light isoflurane anesthesia (3\%), as previously published [26]. Control animals received a similar volume of mineral oil, the diluent for CFA (Sigma Aldrich, St Louis, USA).

Mononeuropathy: To produce a controlled constriction of the sciatic nerve, we used the cuff model which has been well characterized previously in our laboratory [27]. The surgical procedure was carried out under aseptic conditions and ketamine/xylazine anesthesia (ketamine $87 \mathrm{mg} / \mathrm{mL}$, xylazine $13 \mathrm{mg} / \mathrm{mL}$, i.p. (intra-peritoneal) $10 \mathrm{~mL} / \mathrm{kg}$; Centravet, Taden, France). The common branch of the right sciatic nerve was exposed and a $2 \mathrm{~mm}$ long split section of polyethylene tubing (ID $=0.86 \mathrm{~mm}$, $\mathrm{ED}=1.27 \mathrm{~mm}$; PE-90, Harvard Apparatus, Les Ulis, France) was placed around it (Cuff group). The shaved skin layer was then closed using suture. Sham-operated rats underwent the same surgical procedure as described above but without implantation of the cuff (Sham group).

\section{$\underline{\text { Nociceptive tests }}$}

Mechanical nociceptive threshold: Mechanical nociceptive thresholds were measured using a calibrated forceps (Bioseb, Vitrolles, France), as previously described [28]. All animals were 
habituated to the room and the tests, at least one week before the initial experiments. Habituated rats were loosely restrained, with a towel masking the eyes, in order to limit the stress induced by environmental stimulations. The tips of the forceps were placed on each side of the paw and a gradually increasing force was applied. The pressure, in gram, producing withdrawal of the paw or, in some rare cases, vocalization of the animal, was considered as the nociceptive threshold value. This manipulation was performed three times for each hindpaw and values were averaged. All tests were performed between 10:00 AM and 4:00 PM, prior to drug treatment.

Cold allodynia: Thermal cold allodynia was assessed by scoring the aversive behaviors of rats using the acetone test, as previously published [29]. Rats were placed on a wire mesh delimited by a Plexiglas $^{\mathrm{TM}}$ cage and allowed to accommodate for at least $15 \mathrm{~min}$. A drop of acetone was then placed on the ventral side of the hindpaw, producing a non-noxious decrease in temperature during evaporation. The rat behavioral response was scored during $20 \mathrm{~s}$ following acetone application as follows: 0 , no response of the animal; 1 , quick withdrawal, flick or stamp of the paw; 2 , prolonged withdrawal or repeated flicking of the paw; and 3, repeated flicking of the paw with licking of the paw. Manipulation was performed three times for each paw and values were added (maximal score: 9).

\section{Drugs and treatments}

Vitamin D3 (cholecalciferol) was provided in the diet (monoarthritic model) or by gavage (monoarthritic and neuropathic models). Animals were fed with either a control diet (1,000 IU/kg), a vitamin D3-deficient diet (0 IU/kg) or a vitamin D3-supplemented diet (7,500 IU/kg) (INRA, France). If we consider that 300-350 g rats eat approximately 20 grams of chow, the administered doses of vitamin D3 were 60 IU/kg/day, 0 IU/kg/day and $450 \mathrm{IU} / \mathrm{kg} /$ day, respectively. Six weeks were required to reach the vitamin D-deficiency status. In parallel, a group of rats was vitamin D3-supplemented by a weekly gavage (50,000 IU/mL, $200 \mu \mathrm{L} /$ week) (Uvedose, Crinex). Control animals received the same volume of triglycerides, the diluent for vitamin D3. Supplementation, through diet or gavage, was performed during 4 weeks. 


\section{$\underline{\text { ADVIA Centaur }{ }^{\circledR} \text { Vitamin D total analysis }}$}

This assay is a one-step, automated direct competitive chemiluminescent immunoassay that detects 25$\mathrm{OH}$ vitamins D2 and D3 in serum. It employs a proprietary releasing reagent, an anti-fluorescein monoclonal mouse antibody covalently bound to paramagnetic particles, an anti-25(OH)D monoclonal mouse antibody labeled with acridinium ester, and a vitamin D analog labeled with fluorescein. There was an inverse relationship between the resulting chemiluminescent signal detected by the system and the amount of vitamin D present in the sample. This assay is standardized against LC-MS/MS (liquid chromatography coupled to tandem mass spectrometry). The assay range is $9.3 \mathrm{nmol} / \mathrm{L}$ to $375 \mathrm{nmol} / \mathrm{L}$.

\section{Microarray assay}

Lower lumbar DRG, lumbar spinal cord and cerebrum were collected from all groups. Rats were anesthetized with isoflurane before sacrifice and tissues isolated from each animal, before being snapfrozen in liquid nitrogen and stored at $-80^{\circ} \mathrm{C}$ until use. Total RNA was isolated from the snap-frozen tissues using RNeasy Mini kit (Qiagen, Courtaboeuf, France), according to the manufacturer's instructions. RNA concentration was determined using a Nanodrop 2000 spectrophotometer (Life Technologies ThermoFisher Scientific, Villebon sur Yvette, France) and RNA integrity assessed on an Agilent 2100 Bioanalyzer (Agilent Technologies, Les Ulis, France).

RNA samples from 3 animals in each group were pooled for microarray hybridization. Unwanted genomic DNA was removed using a DNase set kit (\#79254, Qiagen). Purified total RNAs were processed for hybridization on genome-wide DNA microarrays within one month. Cyanine-3-labeled cDNA was generated from 300 ng of RNA using the One-Color Low RNA Input Linear Amplification kit (Agilent Technologies) according to the manufacturer's instructions, followed by purification on a RNeasy column (Qiagen). All amplified cDNAs were checked for dye incorporation, cDNA yield and amplification profile. Only those fitting all quality criteria were fragmented for further hybridization onto microarrays. Samples were then carefully hybridized onto Agilent Whole Rat Genome (4644K) 
Oligo Microarrays (G4131F). Microarrays were scanned using an Agilent DNA microarray scanner G2505B. Data are available on the ArrayExpress database (accession number E-MTAB-6801).

\section{$\underline{\text { Microarray data analysis }}$}

Individual microarray quality was evaluated based on quality control report, pair-wise MA-plots (with $\mathrm{M}$ the log ration and A the mean average), and box plots. Intra-array normalization of raw signals from the 8 microarrays (corresponding to the four above-mentioned conditions in duplicates) was performed using Feature Extraction software 9.1.3.1 (Agilent Technologies®). Microarray normalized data were further exported into the Limma package, for inter-array normalization using the quantile method. Statistical analysis was performed using the TIGR MeV (MultiExperiment Viewer) v4.4 software (http://www.tm4.org/mev.html) and the GeneANOVA program. The multi-way ANOVA (analysis of variance) model was implemented: first, to identify differentially regulated genes when accounting for the multiple sources of variation in the microarray experiment; second, to evaluate the effect of the main variable, i.e. the addition of cholecalciferol. Multiple test correction was further carried out using the false discovery rate method. Cluster and Tree View softwares were used for unsupervised hierarchical clustering.

Biological interpretation of the data was performed using Ingenuity Pathway Analysis (IPA, Ingenuity Systems). The main criterion to validate a differentially expressed gene was a fold change over 1.5 or under -1.5 when considering expression values in the group supplemented with vitamin D3 relative to the control diet group, whether considering control or experimental animals. Upregulated and downregulated genes were analyzed in the same data sets to obtain the biologically relevant function categories. Right-tailed Fisher's exact test was used to calculate a p-value determining the top statistically significant biological functions assigned to the data set. 


\section{$\underline{\text { Real-time quantitative PCR (RT-qPCR) }}$}

Tissue from cerebrum and lower lumbar DRG of all animal groups were collected, reconstituted in a guanidine thiocyanate $/ \beta$-mercaptoethanol preparation using ultraturax and stored at $-80^{\circ} \mathrm{C}$. Total RNA was extracted according to a protocol derived from the original procedure of Chomczynski and Sacchi [30], consisting of two independent total RNA extractions separated by a DNAseI treatment (TURBO DNaseTM, Ambion, Life technologies, Saint Aubin, France), as previously described in detail [31]. 800ng RNA were used for reverse transcription with the RT iScript kit (Bio-Rad, Marnes-la-Coquette, France). RT-qPCR was performed using SYBR Green Supermix (Bio-Rad), on the iQ5 Real Time PCR System (Bio-Rad). Amplifications were carried out in 42 cycles $\left(20 \mathrm{~s}\right.$ at $95^{\circ} \mathrm{C}, 20 \mathrm{~s}$ at $60^{\circ} \mathrm{C}$ and $20 \mathrm{~s}$ at $72^{\circ} \mathrm{C}$ ). Serial dilutions of samples were used to create standard curves, after which relative gene expression was calculated as the ratio between cDNA concentration of the gene of interest and that of the housekeeping gene. To specifically amplify mRNA encoding various rat proteins, we designed all our specific primer sets (sense and antisense respectively) to get an optimal annealing efficacy at $60^{\circ} \mathrm{C}$ using Oligo6.0 and M-fold software for selected genes. Primer sequences and their spanning regions in NCBI sequences are given in supplementary table 1.

To standardize the experiments, four classic housekeeping genes were tested; i.e beta2-microglobulin (B2m), glyceraldehyde-3-phosphate dehydrogenase (GAPDH), $\beta$-glucuronidase and hypoxanthine guanine phosphoribosyl transferase (HPRT). Preliminary experiments showed that HPRT transcripts were very stable between samples. Therefore, HPRT was selected as the housekeeping gene. Samples were accurately dispensed in duplicates using a robotic workstation (Freedom EVO100, Tecan, Lyon, France), and amplification efficacy given by standard curves was always close to $100 \%( \pm 2 \%)$, whilst amplification specificity was assessed by a melting curve study.

\section{$\underline{\text { Statistics }}$}

All data are expressed as mean \pm standard error of the mean (SEM). Two-way repeated-measures analysis of variance (RM tw ANOVA), followed by Bonferroni posthoc tests were used to analyze the 
effects on mechanical/thermal nociception. RT-qPCR results were analyzed with one-way ANOVA followed by Sidak's posthoc test. Differences were considered statistically significant for $\mathrm{p}<0.05$. 


\section{$\underline{\text { Results }}$}

\section{Vitamin D3 supplementation reduces mechanical hyperalgesia in monoarthritic rats}

The modulatory action of vitamin D3 on pain symptoms was first evaluated using a model of transient inflammatory pain induced by a single intra-articular injection of CFA. This classical model of knee monoarthritis rapidly induces a local inflammation associated with mechanical hyperalgesia of the ipsilateral hindpaw (Figure 1a). Compared to control values (just before injection at $\mathrm{t}=0$ : $295.8 \pm 2.4 \mathrm{~g}$ ), mean mechanical nociceptive thresholds dropped significantly to a minimal value of $168.1 \pm 5.9 \mathrm{~g}, 24$ hours after CFA injection $(\mathrm{n}=6)$ in control animals receiving normal food. Mean mechanical nociceptive threshold remained unchanged for the ipsilateral hindpaw of rats injected with the vehicle of CFA (Figure 1b) and for all contralateral hindpaws (data not shown). When present, mechanical hyperalgesia persisted for about 3 weeks since mechanical nociceptive thresholds returned to control values 21 days after CFA injection.

Plasma concentrations of the active metabolite of calcitriol (1,25-dihydroxyvitamin D) were $48.94 \pm 3.42 \mathrm{ng} / \mathrm{mL}(\mathrm{n}=11)$ for rats under normal diet and around $120 \mathrm{ng} / \mathrm{mL}$ for rats supplemented for 4 weeks (food: $119.93 \pm 6.25 \mathrm{ng} / \mathrm{mL}, \mathrm{n}=6$; gavage: $135.20 \pm 9.14 \mathrm{ng} / \mathrm{mL}, \mathrm{n}=5$ ). Data were statistically different from normal food rat group at $\mathrm{p}<0.001$ with the Kruskal-Wallis test $(\mathrm{KW}=16.10)$ followed by Dunn's posthoc test (normal food vs food supplementation: $\mathrm{p}<0.01$; normal food vs normal food+gavage: $\mathrm{p}<0.001$ ).

\section{Figure 1 near here}

After 4 weeks of supplementation with vitamin D3 in their food or by weekly gavage, we found that rat mechanical hyperalgesia was significantly reduced compared to those under normal diet (RM tw ANOVA, time $x$ treatment, $\left.F_{(15,75)}=5.59, \mathrm{p}<0.001\right) .24$ hours after CFA injection, thresholds reached a minimal value of $215.6 \pm 6.9 \mathrm{~g}$ and of $222.4 \pm 10.7 \mathrm{~g}$ for rats receiving vitamin D3 food supplementation $(n=6)$ and gavage $(n=6)$, respectively. Normalized to the mean threshold observed 
in rats under normal diet, these values corresponded to a $30-40 \%$ reduction in hyperalgesia. Accordingly, at the end of week 2, no sign of hyperalgesia was observed in supplemented animals whereas rats from the other groups still displayed significantly lower mean mechanical nociceptive thresholds compared to baseline. No difference in the time course of pain symptoms was observed between the two groups of unsupplemented and vitamin D3-deficient rats (Figure 1a).

\section{Vitamin D limits neuropathic pain symptoms and accelerates recovery}

We then investigated the consequences of vitamin D3 supplementation, using rat gavage for 4 weeks, on a neuropathic pain model induced by a chronic constriction of the sciatic nerve. This wellcharacterized model of neuropathic pain is associated with long-lasting mechanical hyperalgesia and cold allodynia (Figure 2). After the cuff surgery, mechanical hyperalgesia developed as indicated by a decrease in the mean mechanical nociceptive threshold (Figure 2a 1 ). Thresholds were significantly different between the cuff- and sham-operated groups (Figure 2a1: RM tw ANOVA, time x surgery, $\mathrm{F}_{(5,25)}=11.25, \mathrm{p}<0.001 ; \mathrm{n}=6$ rats per group). In respect with cold allodynia measured with the acetone test, differences between sham and cuff groups were also observed (Figure 2a2: RM tw ANOVA, time $\mathrm{x}$ surgery, $\mathrm{F}_{(5,25)}=29.88, \mathrm{p}<0.001 ; \mathrm{n}=6$ rats per group).

\section{Figure 2 near here}

Similarly to the monoarthritic model, animals receiving vitamin D3 supplementation displayed significantly reduced mechanical hyperalgesia ( $\mathrm{RM}$ tw ANOVA, time $\mathrm{x}$ treatment, $\mathrm{F}_{(5,25)}=8.57$, $\mathrm{p}<0.001 ; \mathrm{n}=6$ rats per group) and cold allodynia (RM tw ANOVA, time $\mathrm{x}$ treatment, $\mathrm{F}_{(5,25)}=6.73$, $\mathrm{p}<0.001 ; \mathrm{n}=6$ rats per group) when compared to the unsupplemented group. After one week, hyperalgesia-associated mechanical thresholds raised significantly (control food: $159.97 \pm 8.44 \mathrm{~g}$; control food + gavage: $215.11 \pm 8.13 \mathrm{~g} ; \mathrm{n}=6$ ) while cold allodynia scores diminished significantly (control food: $6.00 \pm 0.68 \mathrm{~g}$; control food + gavage: $3.50 \pm 0.56 \mathrm{~g} ; \mathrm{n}=6$ ). Overall, vitamin D3associated modulation of pain symptoms, after one week of treatment, was about $40.6 \%$ and $45.5 \%$, respectively for mechanical and cold modalities. Mechanical sensitivities and behavioral scores in 
response to acetone reached similar values to sham-operated control animals 3 weeks after surgery. No withdrawal (i.e. re-appearance of pain symptoms) was observed during the following days (data not shown). In this model, spontaneous recovery is observed after 60 to 90 days. Altogether, these data suggest that vitamin D3 supplementation accelerates the recovery of these animals as demonstrated by the rapid reduction in pain symptoms.

Because neuropathic pain may appear after surgery in some clinical cases, we also evaluated the benefits of introducing an immediate postsurgical vitamin D3 treatment. Figure $2 \mathrm{~b}$ illustrates the time course of mechanical nociceptive thresholds after cuff surgery. The new kinetic profile is very similar to the previous one. Mechanical allodynia was strongly and significantly reduced one week after surgery (RM tw ANOVA, time $\mathrm{x}$ treatment, $\left.\mathrm{F}_{(5,25)}=11.40, \mathrm{p}<0.001\right)$. Moreover, mechanical hypersensitivity fully disappeared 2-3 weeks after surgery in vitamin D3 treated rats whereas control rats still exhibited pain symptoms. It can thus be concluded that vitamin D3 limits pain symptoms in these two models and accelerates recovery from persistent pain states.

\section{Vitamin D3 induces a massive tissue-dependent gene dysregulation}

Since calcitriol exerts most of its biological effects by modulating gene transcription, we then performed transcriptomic experiments in order to investigate possible genomic pathways explaining its modulatory effect on pain symptoms. We analyzed three nervous tissues of interest: DRG, spinal cord and cerebrum. Supplementary table 2 lists the 1,285 genes that were dysregulated, in at least one of the three tissues, after 4 weeks of cholecalciferol supplementation in neuropathic animals. In the cerebrum, the number of under- (187) and over-expressed (145) genes was nearly even. In contrast, in the spinal cord (69 vs 200) and DRG (278 vs 482), dysregulated genes were predominantly over-expressed.

Figure 3a reveals that vitamin D3 supplementation induced a dysregulation of more than twice as many genes in the DRG as compared to the cerebrum or the spinal cord. Interestingly, only three genes - Mrpl43 (Mitochondrial ribosomal protein L43), Myh7 (Myosin Heavy Chain 7) and Synl (Synapsin 1) - were commonly dysregulated in the three nervous tissues, after vitamin D3 treatment. Mrpl43 was 
under-expressed in all three tissues while $M y h 7$ and Synl were under-expressed in the cerebrum but over-expressed in the spinal cord and DRG.

\section{Figure 3 near here}

Using the IPA software, the clustering of the area-specific dysregulated genes indicated that among the top canonical pathways, the ones displaying the highest significance were: the opioid signaling pathway (23 genes), dendritic cell maturation (12) and axonal guidance signaling (37), for the cerebrum, spinal cord and DRG, respectively (Figure 3b). Furthermore, integrin linked kinase (ILK) signaling, via its cytosolic kinase activity and/or modulatory role on nuclear gene expression, stands out as the prime common canonical pathway.

\section{Vitamin D3 modulates nociception and allodynia in a tissue-specific manner}

To unveil the detailed role of vitamin D3 in nociception and allodynia, we narrowed our analysis to the genes that are directly associated with these two functions. As summarized in Figure 3c, when comparing vitamin D3-supplemented with unsupplemented neuropathic rats, we observed 14 and 17 nociception-associated genes which expression was dysregulated in the cerebrum and DRG, respectively. Within these two pools, only one gene - Cx3cll (C-X3-C Motif Chemokine Ligand 1) was commonly dysregulated, although in an inverted way. In regard to allodynia, 8 and 5 genes were dysregulated in the cerebrum and spinal cord, respectively (Figure 3d), none of them being misexpressed in both tissues. Within the cerebrum, three genes that are involved in the modulation of nociception and allodynia - Pdyn, Penk and Pomc - encode major ligands of the opioid signaling pathway (prodynorphin, proenkephalin and proopiomelanocortin, respectively; Figure 4). No allodynia-associated dysregulated gene was observed in the DRG and no nociception-associated dysregulated gene was noticed in the spinal cord. The 23 genes associated with opioid signaling (Figure 4) are: Adcy5, Ap2b1, Ap2s1, Ctnnb1, Fos, Gnal, Gnas, Gng7, Gsk3b, Itprl, Myc, Pde1b, Pdyn, Penk, Plcb1, Pomc, Ppp3ca, Prkcb, Prkcd, Rgs3, Rgs9, Sos1, Th. 
At this point, we decided to validate the observed expression of several dysregulated genes of our data set, using RT-qPCR performed on samples extracted from animals having received sham or sciatic cuff surgery with or without vitamin D3 supplementation. We chose to sort out the data from both DRG and cerebrum tissues, using three major classes of genes. First, we focused on the opioid system (Figure 5) in cerebrum samples. We observed that pro-dynorphin and pro-enkephalin transcripts were up-regulated in injury conditions but returned to basal levels after vitamin D3 treatment. Conversely, the Pomc gene, known to give rise to many endogenous opioid peptides including met-enkephalin and $\beta$-endorphin, was overexpressed in cuff animals supplemented with vitamin D3. In addition, opioid receptors remained unaffected in our paradigm, promoting the hypothesis that the analgesic endogenous opioid pathways may actively participate in vitamin D actions. This activation appears quite selective since DRG samples extracted from the very same animals did not show a similar pattern.

\section{Figure 5 near here}

A second class of genes (Supplementary Figure 1) which raised our attention includes numerous neurotransmitters/neuropeptides and neurotrophic factors. Here we show that differential patterns of secreted molecules expressed in the DRG and cerebrum are modulated by nerve injury and vitamin D3 supplementation. Indeed, cerebral Avp (vasopressin), Oxt (oxytocin), Adcyapl (PACAP), Gal (galanin) and Hcrt (orexin) genes were significantly up-regulated by vitamin D3 in cuffed condition whilst other such as Tacl (tachikinin) and Npy (neuropeptide Y), which expression is exacerbated by the lesion, returned to basal levels upon vitamin D administration. In the DRG, similar situations have been observed with $G d n f$ (glial cell derived neurotrophic factor), $N g f$ (nerve growth factor), Gdf10 (growth differenciation factor 10), Nrtn (neurturin) and $\mathrm{Ngrl}$ (neuregulin 1) transcripts going up after vitamin D3 supplementation of injured animals and $N p p b$ (encoding the precursor of the brain natriuretic peptide) gene expression enhanced in cuffed condition but restored by vitamin D3.

Finally a last set of genes (Supplementary Figure 2), dealing with inflammation and extracellular matrix remodeling, was also scrutinized in our analysis. RT-qPCR confirmed that, in the cerebrum, 
Cx3cll and Adam11 (metalloprotease) gene up-regulation observed in cuffed condition was abrogated by vitamin D3 treatment whilst Timp4 (a member of the metalloprotease inhibitor family) was solely up-regulated in vitamin D3-treated cuffed samples. In line with these findings, we also observed changes in Cxcl14 (C-X-C Motif Chemokine Ligand 14), Cx3cll and Ccl21b (C-C Motif Chemokine Ligand 21) chemokine transcript levels in DRG with Cxcl14 and Ccl21b up-regulated in cuffed condition and $C x 3 c l 1$ mRNA by vitamin D3 instead. A similar situation was observed for extracellular matrix remodeling with $M m p 9$ and Mmp16 (matrix metallopeptidases 9 and 16) expression enhanced by the lesion and Adamts12 (metalloprotease with thrombospondin) solely up-regulated after vitamin D3 treatment.

\section{Nociception and allodynia may be modulated by inactive and active forms of vitamin D}

To further decipher the modes of action of vitamin D and its metabolites, we used the IPA software to identify the intermediate regulators linking vitamin D3 to the misexpressed genes that, within the cerebrum, are associated with allodynia, nociception and opioid signaling. Our research was focused on calcitriol, the active form, but also on its two precursors: cholecalciferol and calcidiol. Figure 6 indicates that cholecalciferol, calcidiol and calcitriol are associated with 9, 8 and 24 dysregulated genes, respectively. The three metabolites regulate a common pool of 5 genes: Ctnnb1, Fos, Myc, Pomc, Th.

\section{Figure 6 near here}

Each molecule acts in its own way. Cholecalciferol and calcidiol share a similar outcome but none of the intermediate regulators. Many genes associated with cholecalciferol are part of the pool of transcripts regulated by calcitriol (Figures 6a, c). Conversely, calcidiol stands out as the only molecule that is linked to a modified expression of Itprl (Inositol 1,4,5-Triphosphate Receptor Type 1; Figure 6b). Calcitriol is associated to the highest number of transcripts of interest and operates through two levels of regulators (Figure 6c). 
We next explored the tissue-specific mechanisms and compared the consequences of vitamin D3 supplementation on gene expression. In the interest of simplification, we show here the metabolic pathways associated with cholecalciferol. Supplementary figure 3 reveals a similar profile with 5 common signaling regulators - Erk1/2 (i.e. Mapk3/1), Jnk (i.e. Mapk8), P38Mapk (i.e. Mapk14), Prkca, Smad - for the three tissues. Nevertheless, the final result differs dramatically from one tissue to another. 


\section{$\underline{\text { Discussion }}$}

Notwithstanding accumulating evidence indicating that hypovitaminosis D is a risk factor for various forms of pain, the current behavioral and transcriptomic study is, to our knowledge, the first one to assess the effects of a short-term cholecalciferol supplementation in the central (cerebrum and spinal cord) and peripheral (DRG) nervous systems of rats with chronic pain. We observed a dramatic improvement in nociceptive thresholds and allodynia scores as well as a massive and heterogeneous gene dysregulation in the three scrutinized tissues of mononeuropathic animals supplemented with vitamin D3. A large number of dysregulated genes is associated with (i) opioid signaling, nociception and allodynia, in the cerebrum, and (ii) axonal guidance and nociception, in the DRG. Reassuringly, 21 identified cerebral dysregulated genes are associated with vitamin D metabolites and either nociception and/or allodynia and/or opioid signaling. We show here that the anti-nociceptive action of vitamin D3 in the brain involves signaling through Erk1/2 (i.e. Mapk3/1), Map2k1/2, Pth, Src and not, as expected, $V d r$.

\section{A confirmed immuno-modulatory role}

To assess the pain-alleviating effect of cholecalciferol, we first opted for a knee monoarthritis model, in which a transient inflammation is induced by a unilateral injection of CFA. Vitamin D being a potent immune modulator $[32 ; 18 ; 19]$, an impact on inflammatory and immune processes can be expected. Indeed, it has been shown that calcitriol-treated T-cells produced more anti-inflammatory cytokines and less pro-inflammatory cytokines [33-37] for a recent review see [37]. However, unveiling the precise immune-modulatory modes of action of vitamin D was beyond the scope of this study. We chose instead to detail the molecular mechanisms underlying vitamin D3 anti-nociceptive effects in a supposedly non-inflammatory model, namely mononeuropathy.

Claiming that this model is devoid of inflammation would be misleading, as it is associated with a moderate inflammation, highlighted by an altered expression of several inflammatory-related genes, which can be improved by vitamin D3 supplementation. For example, Clqa, Clqc, Ill3ral and Irf2 
(coding for Complement C1q A and C chains, Interleukin 13 receptor subunit alpha 1 and Interferon regulatory factor 2, respectively), over-expressed in unsupplemented animals, are down-regulated after cholecalciferol treatment. To a degree, this immuno-modulatory action may explain the reduced pain symptoms.

\section{A Pomc-related pain relief}

The modulation of opioid signaling by vitamin D3 is one of the major findings of our study. Among the 23 cerebral dysregulated genes that are part of this pathway, three - Pdyn, Penk, Pomc - are noticeable in the cerebrum since they code for endogenous opioids - prodynorphin, dynorphin, leuenkephalin, met-enkephalin, $\beta$-endorphin - that are involved in the sensory perception of pain [38]. An intriguing finding is the imbalanced expression of the P trio: Pomc (+5.4) is up-regulated while Pdyn (2.8) and Penk (-2.6) are down-regulated. Although a few studies indicate a differential modulation of these three transcripts $[39 ; 40 ; 3]$, such a disparity is hard to comprehend. However, Pdyn, Penk, Pomc belong to the opioid/orphanin gene family but they are not (i) located on the same chromosome, (ii) expressed by identical brain areas or cell types nor (iii) regulated by the same molecules. For instance, Pdyn and Penk expression is potentially modulated by Adora2a (adenosine A2a receptor) and Drd2 (dopamine receptor D2) [41] while Pomc is regulated by Avp [42]. Interestingly, the latter is overexpressed in the cerebrum and the formers are under-expressed. Likewise, Fos, which modulates the expression of Pomc [43], is over-expressed whereas Ctnnb1, potential regulator of Pdyn, is underexpressed. This differential regulation could explain the results obtained in this study.

In addition to the altered expression of three opioid agonists, not associated with a modified transcription of opioid receptors, our study reveals a substantial dysregulation of $\mathrm{G}$ proteins subunits and second messengers. When delivered acutely, opioid agonists inhibit adenylyl cyclase (AC) activity [44], as observed here for Adcy5. Conversely, a chronic opioid treatment increases AC levels, inducing a superactivation of cAMP which leads to opioid tolerance and dependence [45]. After binding of the agonists, opioid receptors go through a phosphorylation process triggered by G protein-coupled 
receptor kinases (GRK) and second messenger-regulated kinases (PKC, PKA, CaMK - protein kinases $\mathrm{C}$ and $\mathrm{A}$, and $\mathrm{Ca}^{2+} /$ calmodulin-dependent protein kinases). Here, we observed a down-regulation of Prkcb (protein kinase $\mathrm{C}$ beta) and an up-regulation of Prkcd (protein kinase C delta). These findings are in accordance with the observed cerebral under-expression of IGF2 (insulin like growth factor 2) and over-expression of tumor necrosis factor (TNF), potential specific regulators of each protein kinase, respectively [46; 47].

Finally, in order to further understand the potential role of POMC-derived cleavage peptides in pain alleviation, it is of prime importance to quote a study that assessed the role of $\beta$-endorphin in pain control [48]. When exposed to UV radiation, mice produce the POMC-derived peptide, $\beta$-endorphin, which in turn increases pain-related thresholds. It is therefore conceivable that the reported pain relief is a consequence of an increased production of vitamin D, collateral advantage of UV exposure.

\section{A tissue-specific reaction to painful stimuli}

If we exclude the three genes coding for opioids, 11 and 5 cerebral transcripts are associated with nociception and allodynia, respectively. In most cases, their up- or down-regulation is in accordance with their reported effect. Inhibition of Cx3cll [49], knockout of Adora2a [50; 41] and Tacl genes [51] increase the threshold of mechanical and/or thermal nociception, while central administration of oxytocin enhances analgesia [52] and activation of orexin A (product of $\mathrm{Hcrt}$ ) reduces hot plate nociceptive responses [53]. Contrariwise, knockout of Tphl (tryptophane hydroxylase 1) decreases the threshold of thermal nociception [54] and Aloxe3 (arachidonate lipoxygenase 3) expression is increased in peripheral inflammation [55]. Aquaporin 1, alpha-2 adrenoreceptors (Adra2c) and histidine decarboxylase (Hdc) are also associated with nociception but their over-expression should not induce hypo-nociception [56-58]. In contrast, up- and down-regulation of Aloxe3, Gal and Tgfbl do not fit with previous reports $[59 ; 55 ; 60]$.

In recent years, vitamin D has been described as a cell-, tissue-, time-, individual-, dose-, pathologyand gender-dependent neurosteroid $[3 ; 1]$. Here, discrepancies observed with the transcriptomic study 
are exclusively correlated with the variety of examined tissues. The differences are far from trivial since not a single allodynia-associated dysregulated gene in the cerebrum is detected in the spinal cord and vice versa. Once again, some observations are in accordance with published data. Knockout of Ptgs 2 and Prx increasing allodynia [61; 62], it can be expected that an overexpression of these genes would lead to reduced allodynia. Conversely, a putative anti-allodynic effect of over-expressed Il6, Lepr and Thbs 4 is more difficult to comprehend since interference of active interleukin 6 and thrombospondin 4 (TSP-4, product of Thbs4) and knockout of Lepr and Thbs4 decrease allodynia [63$65]$.

The nociception-associated transcriptomic profile in the DRG is also radically different from that observed in the cerebrum. Only one gene $(\mathrm{Cx} 3 \mathrm{cll})$ out of 17 is commonly dysregulated in DRG and the cerebrum, although in an inverted way. Here again, alleviated pain could result from the over- or under-expression of most of the dysregulated genes. For example, it has been observed that knockouts of Cdk5r1, Trpm8 increase [66;67] and knockout of Gnaol decreases the threshold of thermal nociception [68], three findings in accordance with their respective under- and over-expression in the DRG. Neural cell adhesion molecule (NCAM) signaling mediates the analgesic effect of GDNF which we found overexpressed in the cerebrum [69], NOGO-66 (product of $R \operatorname{tn} 4$ ) reduces neuropathic pain after sciatic nerve transection [70] and NGF is involved in the sensory perception of pain [71].

New clues on vitamin D3-related molecular mechanisms in the nervous system

Studies have shown that the VDR is very poorly expressed in the central nervous system $[72 ; 73 ; 2]$ and only a restricted number of cerebral genes contain an upstream VDRE (Vitamin D response element) [74]. In conformity with these previous findings, the current study indicates that, at most, the expression of three nociception- and cholecalciferol-related genes is regulated by the VDR. And, out of three, only one (Ngf) displays a VDRE [74].

The current transcriptomic study provides new clues on potential and/or established intermediate regulators. Instead of up- or down-regulating gene transcription via a VDR/VDRE mechanism, 
calcitriol may trigger activation or inhibition of some key proteins. This first row of regulators (MAP2K 1/2, ERK 1/2 (i.e. MAPK3/1), SRC, PTH, SMAD3) activates or inhibits a second row of proteins which, in turn, modulates the expression of the final effectors. This is in line with results from other studies done in human hepatocytes [75], chondrocytes, [76-78], keratinocytes and colonocytes [79]. Our study also suggests that calcidiol may not be as "inactive" as it is supposed to be, and does not need to be further hydroxylated to be efficient. This is in accordance with a study in which 25 hydroxycholesterol was shown to amplify inflammatory signaling by mediating the recruitment of the activator protein 1 (AP-1) components of Fos and Jun to the promoters of a subset of Toll-like receptor-responsive genes [80]. It should be noted that the metabolic pathway suggesting that cholecalciferol may be active as well should be analyzed with caution as the proposed scheme comes from publications in which [1,25-hydroxycholesterol] (calcitriol) is mislabeled as cholecalciferol.

\section{Recommendations for a clinical translation}

Since recent reviews and meta-analyses deliver a mixed message about the potential therapeutic benefit of vitamin D2 or D3 supplementation against acute and chronic pain, reliable randomized, placebo-controlled clinical trials with undisputed conclusions remain to be performed. Among the major pre-requisites, vitamin D and its time/mode of administration, as well as the patient's geno/phenotype, should be taken into account. 
Acknowledgments: This work was supported by the following French institutions: Centre National de la Recherche Scientifique, Fondation de l'Avenir, Université de Strasbourg and Institut Universitaire de France. MA and GG received PhD scholarship from the French Ministère de la Recherche et de 1'Enseignement Supérieur. We thank the following research programs of excellence for their support: FHU Neurogenycs, French National Research Agency (ANR) through the Programme d'Investissement d'Avenir (contract ANR-17-EURE-0022, EURIDOL graduate school of pain).

\section{Conflict of interest statement}

The authors declare that they have no conflict of interest. 


\section{$\underline{\text { References }}$}

[1]Cui X, Gooch H, Petty A, McGrath JJ, Eyles D. Vitamin D and the brain: Genomic and nongenomic actions. Mol Cell Endocrinol 2017;453:131-143.

[2]Landel V, Stephan D, Cui X, Eyles D, Feron F. Differential expression of vitamin D-associated enzymes and receptors in brain cell subtypes. J Steroid Biochem Mol Biol 2017.

[3]Landel V, Annweiler C, Millet P, Morello M, Feron F. Vitamin D, Cognition and Alzheimer's Disease: The Therapeutic Benefit is in the D-Tails. J Alzheimers Dis 2016;53(2):419-444.

[4]Plotnikoff GA, Quigley JM. Prevalence of severe hypovitaminosis D in patients with persistent, nonspecific musculoskeletal pain. Mayo Clin Proc 2003;78(12):1463-1470.

[5]Lotfi A, Abdel-Nasser AM, Hamdy A, Omran AA, El-Rehany MA. Hypovitaminosis D in female patients with chronic low back pain. Clin Rheumatol 2007;26(11):1895-1901.

[6]Mouyis M, Ostor AJ, Crisp AJ, Ginawi A, Halsall DJ, Shenker N, Poole KE. Hypovitaminosis D among rheumatology outpatients in clinical practice. Rheumatology (Oxford) 2008;47(9):13481351.

[7]Atherton K, Berry DJ, Parsons T, Macfarlane GJ, Power C, Hypponen E. Vitamin D and chronic widespread pain in a white middle-aged British population: evidence from a cross-sectional population survey. Ann Rheum Dis 2009;68(6):817-822.

[8]Tague SE, Clarke GL, Winter MK, McCarson KE, Wright DE, Smith PG. Vitamin D deficiency promotes skeletal muscle hypersensitivity and sensory hyperinnervation. J Neurosci 2011;31(39):13728-13738.

[9]Wepner F, Scheuer R, Schuetz-Wieser B, Machacek P, Pieler-Bruha E, Cross HS, Hahne J, Friedrich M. Effects of vitamin D on patients with fibromyalgia syndrome: a randomized placebo-controlled trial. Pain 2014;155(2):261-268.

[10]Schreuder F, Bernsen RM, van der Wouden JC. Vitamin D supplementation for nonspecific musculoskeletal pain in non-Western immigrants: a randomized controlled trial. Ann Fam Med 2012;10(6):547-555.

[11]Straube S, Andrew Moore R, Derry S, McQuay HJ. Vitamin D and chronic pain. Pain 2009;141(12):10-13.

[12]Shipton EE, Shipton EA. Vitamin D Deficiency and Pain: Clinical Evidence of Low Levels of Vitamin D and Supplementation in Chronic Pain States. Pain Ther 2015;4(1):67-87.

[13]Straube S, Derry S, Straube C, Moore RA. Vitamin D for the treatment of chronic painful conditions in adults. Cochrane Database Syst Rev 2015(5):CD007771.

[14]Wu Z, Malihi Z, Stewart AW, Lawes CM, Scragg R. Effect of Vitamin D Supplementation on Pain: A Systematic Review and Meta-analysis. Pain Physician 2016;19(7):415-427.

[15]de Oliveira DL, Hirotsu C, Tufik S, Andersen ML. The interfaces between vitamin D, sleep and pain. J Endocrinol 2017;234(1):R23-R36.

[16]Yong WC, Sanguankeo A, Upala S. Effect of vitamin D supplementation in chronic widespread pain: a systematic review and meta-analysis. Clin Rheumatol 2017;36(12):2825-2833.

[17]Helde-Frankling M, Bjorkhem-Bergman L. Vitamin D in Pain Management. Int J Mol Sci 2017;18(10).

[18]Colotta F, Jansson B, Bonelli F. Modulation of inflammatory and immune responses by vitamin D. J Autoimmun 2017;85:78-97.

[19]Sassi F, Tamone C, D'Amelio P. Vitamin D: Nutrient, Hormone, and Immunomodulator. Nutrients 2018;10(11).

[20]Liu X, Nelson A, Wang X, Farid M, Gunji Y, Ikari J, Iwasawa S, Basma H, Feghali-Bostwick C, Rennard SI. Vitamin D modulates prostaglandin E2 synthesis and degradation in human lung fibroblasts. Am J Respir Cell Mol Biol 2014;50(1):40-50.

[21]Gendelman O, Itzhaki D, Makarov S, Bennun M, Amital H. A randomized double-blind placebocontrolled study adding high dose vitamin $\mathrm{D}$ to analgesic regimens in patients with musculoskeletal pain. Lupus 2015;24(4-5):483-489. 
[22]Huang W, Shah S, Long Q, Crankshaw AK, Tangpricha V. Improvement of pain, sleep, and quality of life in chronic pain patients with vitamin D supplementation. Clin J Pain 2013;29(4):341-347.

[23]Banafshe HR, Khoshnoud MJ, Abed A, Saghazadeh M, Mesdaghinia A. Vitamin D supplementation attenuates the behavioral scores of neuropathic pain in rats. Nutr Neurosci 2018:1-6.

[24]Chabas JF, Stephan D, Marqueste T, Garcia S, Lavaut MN, Nguyen C, Legre R, Khrestchatisky M, Decherchi P, Feron F. Cholecalciferol (vitamin D(3)) improves myelination and recovery after nerve injury. PLoS One 2013;8(5):e65034.

[25]Montava M, Garcia S, Mancini J, Jammes Y, Courageot J, Lavieille JP, Feron F. Vitamin D3 potentiates myelination and recovery after facial nerve injury. Eur Arch Otorhinolaryngol 2015;272(10):2815-2823.

[26]Aouad M, Zell V, Juif PE, Lacaud A, Goumon Y, Darbon P, Lelievre V, Poisbeau P. Etifoxine analgesia in experimental monoarthritis: a combined action that protects spinal inhibition and limits central inflammatory processes. Pain 2014;155(2):403-412.

[27]Aouad M, Petit-Demouliere N, Goumon Y, Poisbeau P. Etifoxine stimulates allopregnanolone synthesis in the spinal cord to produce analgesia in experimental mononeuropathy. Eur J Pain 2014;18(2):258-268.

[28]Luis-Delgado OE, Barrot M, Rodeau JL, Schott G, Benbouzid M, Poisbeau P, Freund-Mercier MJ, Lasbennes F. Calibrated forceps: a sensitive and reliable tool for pain and analgesia studies. J Pain 2006;7(1):32-39.

[29]Aouad M, Charlet A, Rodeau JL, Poisbeau P. Reduction and prevention of vincristine-induced neuropathic pain symptoms by the non-benzodiazepine anxiolytic etifoxine are mediated by 3alpha-reduced neurosteroids. Pain 2009;147(1-3):54-59.

[30]Chomczynski P, Sacchi N. Single-step method of RNA isolation by acid guanidinium thiocyanatephenol-chloroform extraction. Anal Biochem 1987;162(1):156-159.

[31]Lelievre V, Hu Z, Byun JY, Ioffe Y, Waschek JA. Fibroblast growth factor-2 converts PACAP growth action on embryonic hindbrain precursors from stimulation to inhibition. J Neurosci Res 2002;67(5):566-573.

[32]Fernandes de Abreu DA, Eyles D, Feron F. Vitamin D, a neuro-immunomodulator: implications for neurodegenerative and autoimmune diseases. Psychoneuroendocrinology 2009;34 Suppl $1:$ S265-277.

[33]Lemire JM, Archer DC, Beck L, Spiegelberg HL. Immunosuppressive actions of 1,25dihydroxyvitamin D3: preferential inhibition of Th1 functions. J Nutr 1995;125(6 Suppl):1704S-1708S.

[34]Boonstra A, Barrat FJ, Crain C, Heath VL, Savelkoul HF, O'Garra A. 1alpha,25Dihydroxyvitamin $\mathrm{d} 3$ has a direct effect on naive CD4(+) T cells to enhance the development of Th2 cells. J Immunol 2001;167(9):4974-4980.

[35]Jeffery LE, Burke F, Mura M, Zheng Y, Qureshi OS, Hewison M, Walker LS, Lammas DA, Raza K, Sansom DM. 1,25-Dihydroxyvitamin D3 and IL-2 combine to inhibit T cell production of inflammatory cytokines and promote development of regulatory $\mathrm{T}$ cells expressing CTLA-4 and FoxP3. J Immunol 2009;183(9):5458-5467.

[36]Cantorna MT, Waddell A. The vitamin D receptor turns off chronically activated T cells. Ann N Y Acad Sci 2014;1317:70-75.

[37]Bivona G, Agnello L, Ciaccio M. The immunological implication of the new vitamin D metabolism. Cent Eur J Immunol 2018;43(3):331-334.

[38]Navarro S, Soletto L, Puchol S, Rotllant J, Soengas JL, Cerda-Reverter JM. 60 YEARS OF POMC: POMC: an evolutionary perspective. J Mol Endocrinol 2016;56(4):T113-118.

[39]Staszkiewicz J, Skowronski MT, Siawrys G, Kaminski T, Krazinski BE, Plonka KJ, Wylot B, Przala J, Okrasa S. Expression of proopiomelanocortin, proenkephalin and prodynorphin genes in porcine luteal cells. Acta Vet Hung 2007;55(4):435-449. 
[40]Wylot B, Staszkiewicz J, Okrasa S. The expression of genes coding for opioid precursors, opioid receptors, beta-LH subunit and GnRH receptor in the anterior pituitary of cyclic gilts. J Physiol Pharmacol 2008;59(4):745-758.

[41]Xu K, Bastia E, Schwarzschild M. Therapeutic potential of adenosine A(2A) receptor antagonists in Parkinson's disease. Pharmacol Ther 2005;105(3):267-310.

[42]van de Pavert SA, Clarke IJ, Rao A, Vrana KE, Schwartz J. Effects of vasopressin and elimination of corticotropin-releasing hormone-target cells on pro-opiomelanocortin mRNA levels and adrenocorticotropin secretion in ovine anterior pituitary cells. J Endocrinol 1997;154(1):139147.

[43]Bousquet C, Zatelli MC, Melmed S. Direct regulation of pituitary proopiomelanocortin by STAT3 provides a novel mechanism for immuno-neuroendocrine interfacing. J Clin Invest 2000;106(11):1417-1425.

[44]Bian JM, Wu N, Su RB, Li J. Opioid receptor trafficking and signaling: what happens after opioid receptor activation? Cell Mol Neurobiol 2012;32(2):167-184.

[45]Koch T, Hollt V. Role of receptor internalization in opioid tolerance and dependence. Pharmacol Ther 2008;117(2):199-206.

[46]El-Shewy HM, Abdel-Samie SA, Al Qalam AM, Lee MH, Kitatani K, Anelli V, Jaffa AA, Obeid LM, Luttrell LM. Phospholipase C and protein kinase C-beta 2 mediate insulin-like growth factor II-dependent sphingosine kinase 1 activation. Mol Endocrinol 2011;25(12):2144-2156.

[47]Farnsworth NL, Walter RL, Hemmati A, Westacott MJ, Benninger RK. Low Level Proinflammatory Cytokines Decrease Connexin36 Gap Junction Coupling in Mouse and Human Islets through Nitric Oxide-mediated Protein Kinase Cdelta. J Biol Chem 2016;291(7):31843196.

[48]Fell GL, Robinson KC, Mao J, Woolf CJ, Fisher DE. Skin beta-endorphin mediates addiction to UV light. Cell 2014;157(7):1527-1534.

[49]Souza GR, Talbot J, Lotufo CM, Cunha FQ, Cunha TM, Ferreira SH. Fractalkine mediates inflammatory pain through activation of satellite glial cells. Proc Natl Acad Sci U S A 2013;110(27):11193-11198.

[50]Ledent C, Vaugeois JM, Schiffmann SN, Pedrazzini T, El Yacoubi M, Vanderhaeghen JJ, Costentin J, Heath JK, Vassart G, Parmentier M. Aggressiveness, hypoalgesia and high blood pressure in mice lacking the adenosine A2a receptor. Nature 1997;388(6643):674-678.

[51]Inoue M, Shimohira I, Yoshida A, Zimmer A, Takeshima H, Sakurada T, Ueda H. Dose-related opposite modulation by nociceptin/orphanin FQ of substance P nociception in the nociceptors and spinal cord. J Pharmacol Exp Ther 1999;291(1):308-313.

[52]Yang J, Yang Y, Chen JM, Liu WY, Wang CH, Lin BC. Effect of oxytocin on acupuncture analgesia in the rat. Neuropeptides 2007;41(5):285-292.

[53]Ho YC, Lee HJ, Tung LW, Liao YY, Fu SY, Teng SF, Liao HT, Mackie K, Chiou LC. Activation of orexin 1 receptors in the periaqueductal gray of male rats leads to antinociception via retrograde endocannabinoid (2-arachidonoylglycerol)-induced disinhibition. J Neurosci 2011;31(41):14600-14610.

[54]Savelieva KV, Zhao S, Pogorelov VM, Rajan I, Yang Q, Cullinan E, Lanthorn TH. Genetic disruption of both tryptophan hydroxylase genes dramatically reduces serotonin and affects behavior in models sensitive to antidepressants. PLoS One 2008;3(10):e3301.

[55]Gregus AM, Dumlao DS, Wei SC, Norris PC, Catella LC, Meyerstein FG, Buczynski MW, Steinauer JJ, Fitzsimmons BL, Yaksh TL, Dennis EA. Systematic analysis of rat 12/15lipoxygenase enzymes reveals critical role for spinal eLOX3 hepoxilin synthase activity in inflammatory hyperalgesia. FASEB J 2013;27(5):1939-1949.

[56]Yoshida A, Mobarakeh JI, Sakurai E, Sakurada S, Orito T, Kuramasu A, Kato M, Yanai K. Intrathecally-administered histamine facilitates nociception through tachykinin NK1 and histamine $\mathrm{H} 1$ receptors: a study in histidine decarboxylase gene knockout mice. Eur J Pharmacol 2005;522(1-3):55-62. 
[57]Oshio K, Watanabe H, Yan D, Verkman AS, Manley GT. Impaired pain sensation in mice lacking Aquaporin-1 water channels. Biochem Biophys Res Commun 2006;341(4):1022-1028.

[58]Roh DH, Seo HS, Yoon SY, Song S, Han HJ, Beitz AJ, Lee JH. Activation of spinal alpha-2 adrenoceptors, but not mu-opioid receptors, reduces the intrathecal N-methyl-D-aspartateinduced increase in spinal NR1 subunit phosphorylation and nociceptive behaviors in the rat. Anesth Analg 2010;110(2):622-629.

[59]Liu HX, Brumovsky P, Schmidt R, Brown W, Payza K, Hodzic L, Pou C, Godbout C, Hokfelt T. Receptor subtype-specific pronociceptive and analgesic actions of galanin in the spinal cord: selective actions via GalR1 and GalR2 receptors. Proc Natl Acad Sci U S A 2001;98(17):99609964.

[60]Lantero A, Tramullas M, Pilar-Cuellar F, Valdizan E, Santillan R, Roques BP, Hurle MA. TGFbeta and opioid receptor signaling crosstalk results in improvement of endogenous and exogenous opioid analgesia under pathological pain conditions. J Neurosci 2014;34(15):53855395.

[61]Gillespie CS, Sherman DL, Fleetwood-Walker SM, Cottrell DF, Tait S, Garry EM, Wallace VC, Ure J, Griffiths IR, Smith A, Brophy PJ. Peripheral demyelination and neuropathic pain behavior in periaxin-deficient mice. Neuron 2000;26(2):523-531.

[62]Chillingworth NL, Morham SG, Donaldson LF. Sex differences in inflammation and inflammatory pain in cyclooxygenase-deficient mice. Am J Physiol Regul Integr Comp Physiol 2006;291(2):R327-334.

[63]Milligan ED, Twining C, Chacur M, Biedenkapp J, O'Connor K, Poole S, Tracey K, Martin D, Maier SF, Watkins LR. Spinal glia and proinflammatory cytokines mediate mirror-image neuropathic pain in rats. J Neurosci 2003;23(3):1026-1040.

[64]Kim DS, Li KW, Boroujerdi A, Peter Yu Y, Zhou CY, Deng P, Park J, Zhang X, Lee J, Corpe M, Sharp K, Steward O, Eroglu C, Barres B, Zaucke F, Xu ZC, Luo ZD. Thrombospondin-4 contributes to spinal sensitization and neuropathic pain states. J Neurosci 2012;32(26):89778987.

[65]Shi TJ, Zhang MD, Zeberg H, Nilsson J, Grunler J, Liu SX, Xiang Q, Persson J, Fried KJ, Catrina SB, Watanabe M, Arhem P, Brismar K, Hokfelt TG. Coenzyme Q10 prevents peripheral neuropathy and attenuates neuron loss in the $\mathrm{db}-/ \mathrm{db}$ - mouse, a type 2 diabetes model. Proc Natl Acad Sci U S A 2013;110(2):690-695.

[66]Pareek TK, Keller J, Kesavapany S, Pant HC, Iadarola MJ, Brady RO, Kulkarni AB. Cyclindependent kinase 5 activity regulates pain signaling. Proc Natl Acad Sci U S A 2006;103(3):791-796.

[67]Bautista DM, Siemens J, Glazer JM, Tsuruda PR, Basbaum AI, Stucky CL, Jordt SE, Julius D. The menthol receptor TRPM8 is the principal detector of environmental cold. Nature 2007;448(7150):204-208.

[68]Jiang M, Gold MS, Boulay G, Spicher K, Peyton M, Brabet P, Srinivasan Y, Rudolph U, Ellison G, Birnbaumer L. Multiple neurological abnormalities in mice deficient in the G protein Go. Proc Natl Acad Sci U S A 1998;95(6):3269-3274.

[69]Sakai A, Asada M, Seno N, Suzuki H. Involvement of neural cell adhesion molecule signaling in glial cell line-derived neurotrophic factor-induced analgesia in a rat model of neuropathic pain. Pain 2008;137(2):378-388.

[70]Li L, Qin H, Shi W, Gao G. Local Nogo-66 administration reduces neuropathic pain after sciatic nerve transection in rat. Neurosci Lett 2007;424(3):145-148.

[71]Chao MV. The p75 neurotrophin receptor. J Neurobiol 1994;25(11):1373-1385.

[72]Wang Y, Zhu J, DeLuca HF. Where is the vitamin D receptor? Arch Biochem Biophys 2012;523(1):123-133.

[73]Eyles DW, Liu PY, Josh P, Cui X. Intracellular distribution of the vitamin D receptor in the brain: comparison with classic target tissues and redistribution with development. Neuroscience 2014;268:1-9. 
[74]Wang TT, Tavera-Mendoza LE, Laperriere D, Libby E, MacLeod NB, Nagai Y, Bourdeau V, Konstorum A, Lallemant B, Zhang R, Mader S, White JH. Large-scale in silico and microarray-based identification of direct 1,25-dihydroxyvitamin D3 target genes. Mol Endocrinol 2005;19(11):2685-2695.

[75]Han S, Li T, Ellis E, Strom S, Chiang JY. A novel bile acid-activated vitamin D receptor signaling in human hepatocytes. Mol Endocrinol 2010;24(6):1151-1164.

[76]Schwartz Z, Ehland H, Sylvia VL, Larsson D, Hardin RR, Bingham V, Lopez D, Dean DD, Boyan BD. 1alpha,25-dihydroxyvitamin $\mathrm{D}(3)$ and 24R,25-dihydroxyvitamin $\mathrm{D}(3)$ modulate growth plate chondrocyte physiology via protein kinase C-dependent phosphorylation of extracellular signal-regulated kinase 1/2 mitogen-activated protein kinase. Endocrinology 2002;143(7):2775-2786.

[77]Peric M, Koglin S, Kim SM, Morizane S, Besch R, Prinz JC, Ruzicka T, Gallo RL, Schauber J. IL-17A enhances vitamin D3-induced expression of cathelicidin antimicrobial peptide in human keratinocytes. J Immunol 2008;181(12):8504-8512.

[78]Shen M, Yen A. Nicotinamide cooperates with retinoic acid and 1,25-dihydroxyvitamin $\mathrm{D}(3)$ to regulate cell differentiation and cell cycle arrest of human myeloblastic leukemia cells. Oncology 2009;76(2):91-100.

[79]Gniadecki R. Nongenomic signaling by vitamin D: a new face of Src. Biochem Pharmacol 1998;56(10):1273-1277.

[80]Gold ES, Diercks AH, Podolsky I, Podyminogin RL, Askovich PS, Treuting PM, Aderem A. 25Hydroxycholesterol acts as an amplifier of inflammatory signaling. Proc Natl Acad Sci U S A 2014;111(29):10666-10671. 


\section{$\underline{\text { Legends }}$}

Fig.1 Time course of mechanical nociceptive thresholds measured from the hindpaw of rats injected with CFA (complete Freund's adjuvant) (a) or its vehicle (b) in the knee joint at Day 0. Comparison is shown for rats fed with a normal or vitamin D3 (vitD3) deficient diet, or vitamin D3-supplemented through diet or by gavage. Comparisons between supplemented and unsupplemented groups are indicated by asterisks at each time point. (\#) indicates statistical significance when comparing values, for each time point, between vehicle- and CFA-injected animals receiving a similar diet. Statistical significance was assessed with Bonferroni posthoc test, illustrated as follows: $\mathrm{p}<0.01(* *)$ and $\mathrm{p}<$ $0.001(* * *$ or \#\#\#).

Fig.2 a. Time course of mechanical nociceptive thresholds $\left(\mathrm{a}_{1}\right)$ and cold allodynia scores $\left(\mathrm{a}_{2}\right)$ measured in sham-operated and cuffed rats, supplemented or not with vitamin D3 (vitD3). b. Time course of mechanical nociceptive thresholds of rats supplemented or not with vitamin D3, from day 0 (time of surgery). Statistical significance was assessed with Bonferroni posthoc test, illustrated as follows: $\mathrm{p}<$ $0.05(*), \mathrm{p}<0.01(* *)$ or $\mathrm{p}<0.001(* * *)$ for comparisons between control and vitamin D3supplemented groups, and $\mathrm{p}<0.05(\#), \mathrm{p}<0.01$ (\#\#) or $\mathrm{p}<0.001$ (\#\#\#) for comparisons between sham and cuffed animals receiving a similar diet, at each time point.

Fig.3 Extensive transcript dysregulation in the cerebrum, spinal cord and dorsal root ganglia (DRG) of rats, 2 days after being fed during 4 weeks with a vitamin D3-supplemented diet. a. Venn diagram showing the number of dysregulated genes in each tissue. The number of genes specifically dysregulated in DRG is more than twice as large as in other tissues. b. Venn diagram indicating the top canonical pathway in each tissue (dend. cell maturation: dendritic cell maturation; ILK: integrin linked kinase). c. Schematic overview of the genes associated with nociception in the cerebrum and DRG. d. 
Schematic overview of the genes associated with allodynia in the cerebrum and spinal cord. Fold change cut off used for above analyses was $-1.5>\mathrm{FC}>1.5$.

Fig.4 Schematic opioid signaling pathway. Cerebral dysregulated genes, associated with opioid signaling, are highlighted (up: red; down: green) in a simplified view of the canonical pathway developed by Ingenuity@.

Fig.5 RT-qPCR validation of several dysregulated transcripts in the dorsal root ganglia (DRG) (top graphs) and cerebrum (bottom graphs) of animals that received sham or cuff surgery with or without vitamin D3 supplementation. The different graphs illustrate the relative gene transcript expression for pro- and pre-pro-opioidergic peptides (POMC: pro-opio-melanocortin; PDYN: prodynorphin; PENK: proenkephalin) as well as for the three main opioid receptors (DOR: delta opioid receptor; KOR: kappa opioid receptor; MOR: mu opioid receptor). Statistical code for Sidak's multiple comparisons test: $* * \mathrm{p}<0.01 ; * * * \mathrm{p}<0.001$

Fig.6 Schematic view of the putative mechanisms of vitamin D3 action in the cerebrum. Cholecalciferol, 25-hydroxycholesterol (calcidiol) and calcitriol are associated with 9, 8 and 24 nociception-, allodynia- and opiod- associated dysregulated genes, respectively. Five genes - Ctnnbl, Fos, Myc, Pomc, Th-are commonly regulated by the three metabolites. Each molecule regulates gene transcription in a specific manner. Regulators are either activated (brown) or inhibited (blue); genes are either up- (red) or down-regulated (green).

Supplementary Fig.1 RT-qPCR validation of several dysregulated transcripts in the dorsal root ganglia (DRG) and cerebrum of animals that received sham or cuff surgery with or without vitamin D3 supplementation. Relative expression of transcripts coding for diverse neurotransmitters, 
neuropeptides and neurotrophic factors. Statistical code for Sidak's multiple comparisons test: *** $\mathrm{p}<0.001$.

Supplementary Fig.2 RT-qPCR validation of several dysregulated transcripts in the dorsal root ganglia (DRG) and cerebrum of animals that received sham or cuff surgery with or without vitamin D3 supplementation. Relative expression of transcripts coding for proteins of the extracellular matrix and some chemokines. Statistical code for Sidak's multiple comparisons test: *** $\mathrm{p}<0.001$.

Supplementary Fig.3 Schematic view of the putative mechanisms of cholecalciferol action in the cerebrum (a), dorsal root ganglia (DRG) (b) and spinal cord (c). Five common regulators - Erk1/2 (i.e. Mapk3/1), Jnk (i.e. Mapk8), P38mapk, Prkca, Smad - are identified, although dysregulated genes differ greatly from one tissue to another. Regulators are either activated (brown) or inhibited (blue); genes are either up- (red) or down-regulated (green).

Supplementary table 1 List of primer sequences used to amplify genes of interest by RT-qPCR.

Supplementary table 2 Alphabetical list of over- (in red) and under-expressed genes (in green) in the dorsal root ganglia (DRG; yellow boxes), the spinal cord (blue boxes) and the cerebrum (green boxes) of cuff-operated rats supplemented with vitamin D3 compared with unsupplemented animals. 

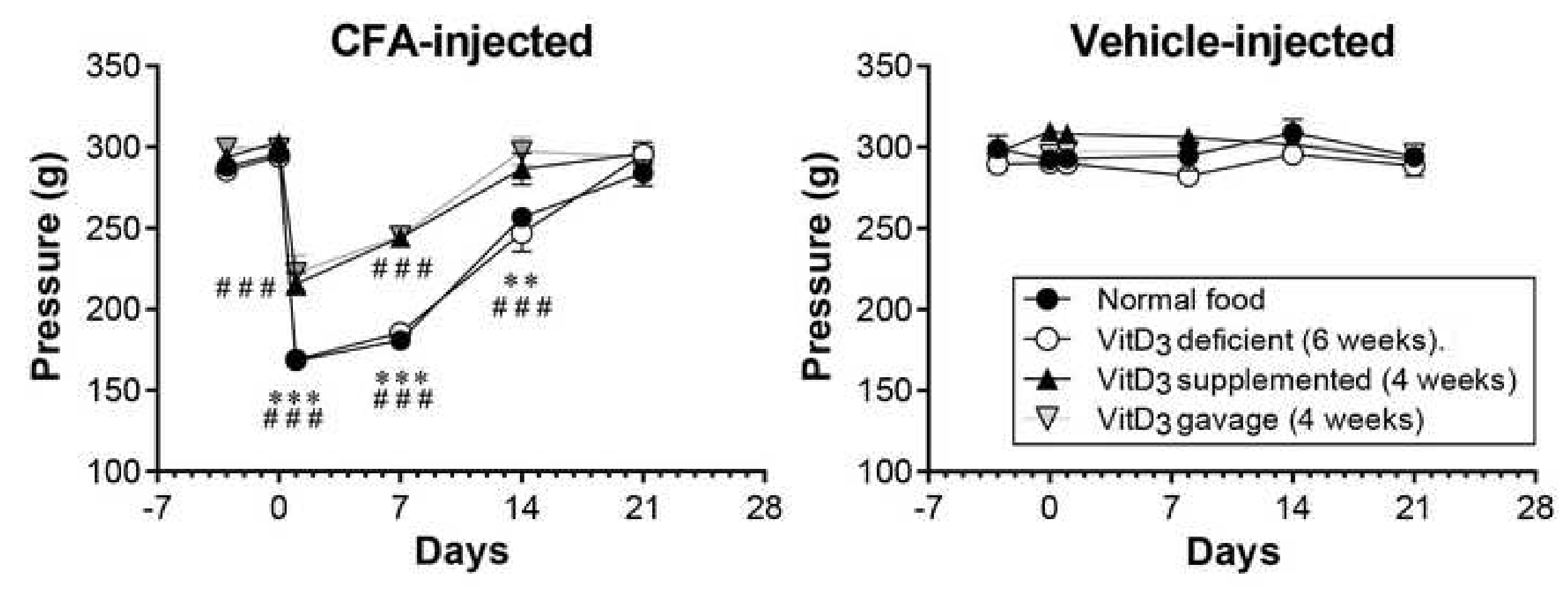

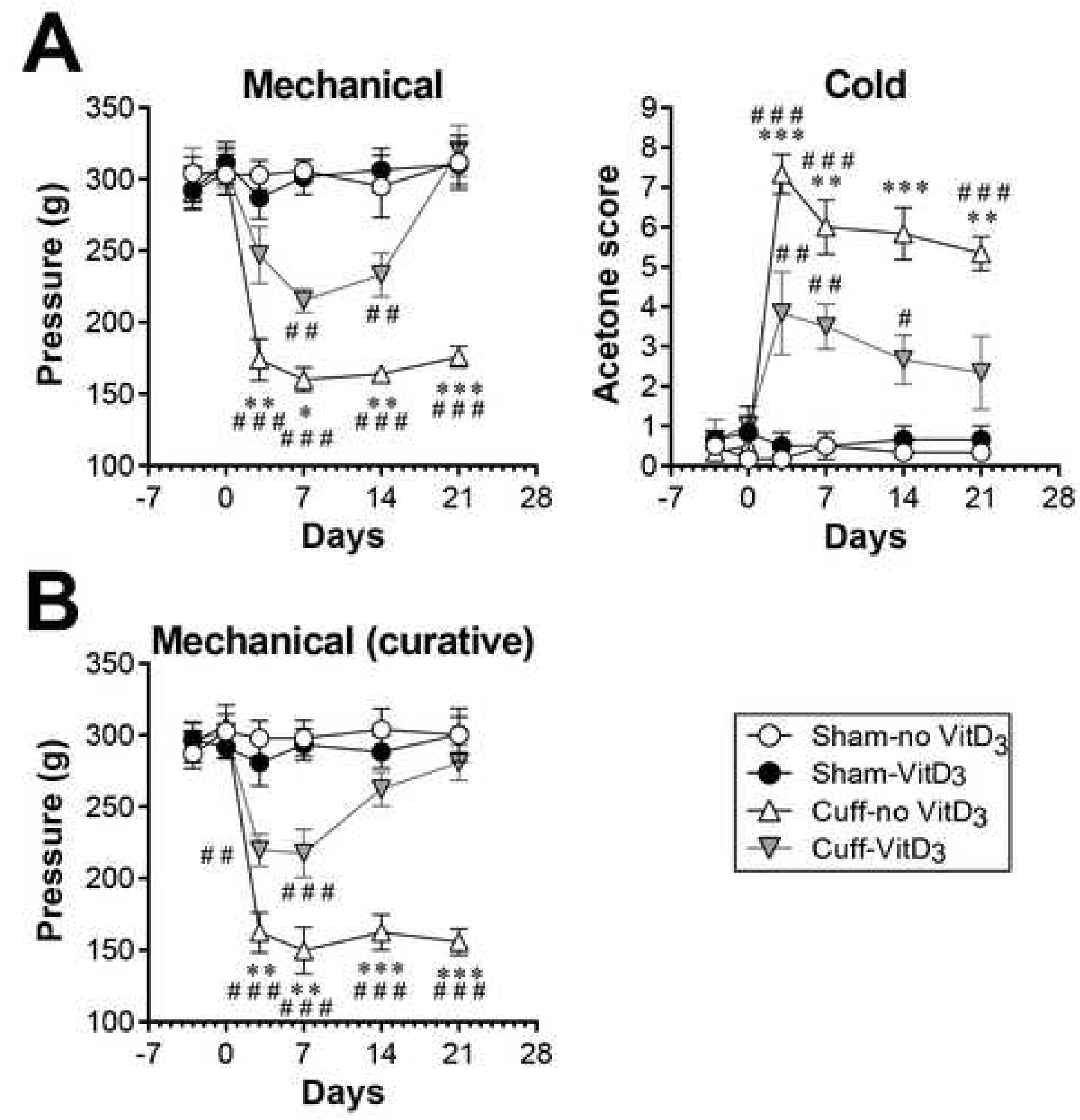

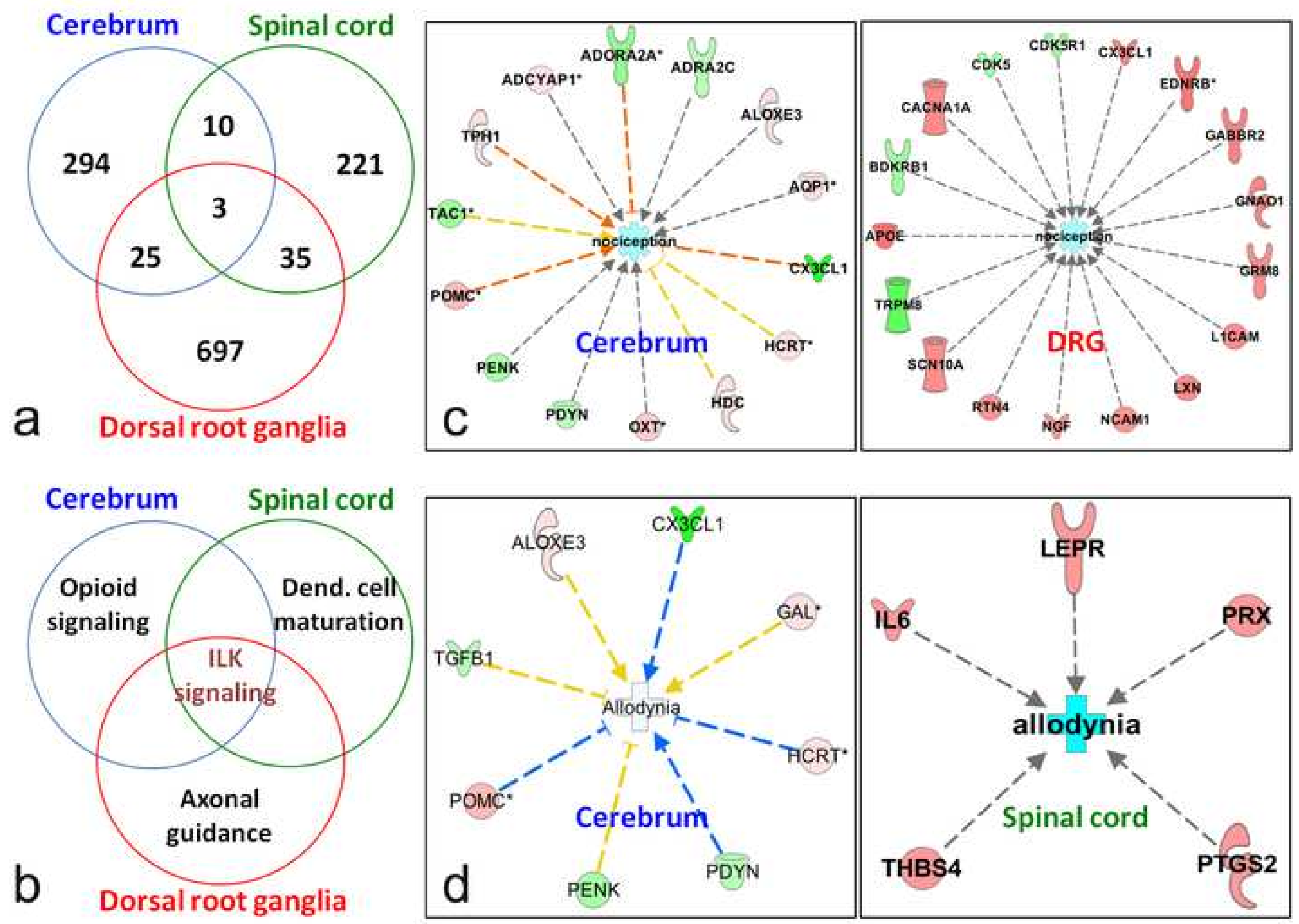


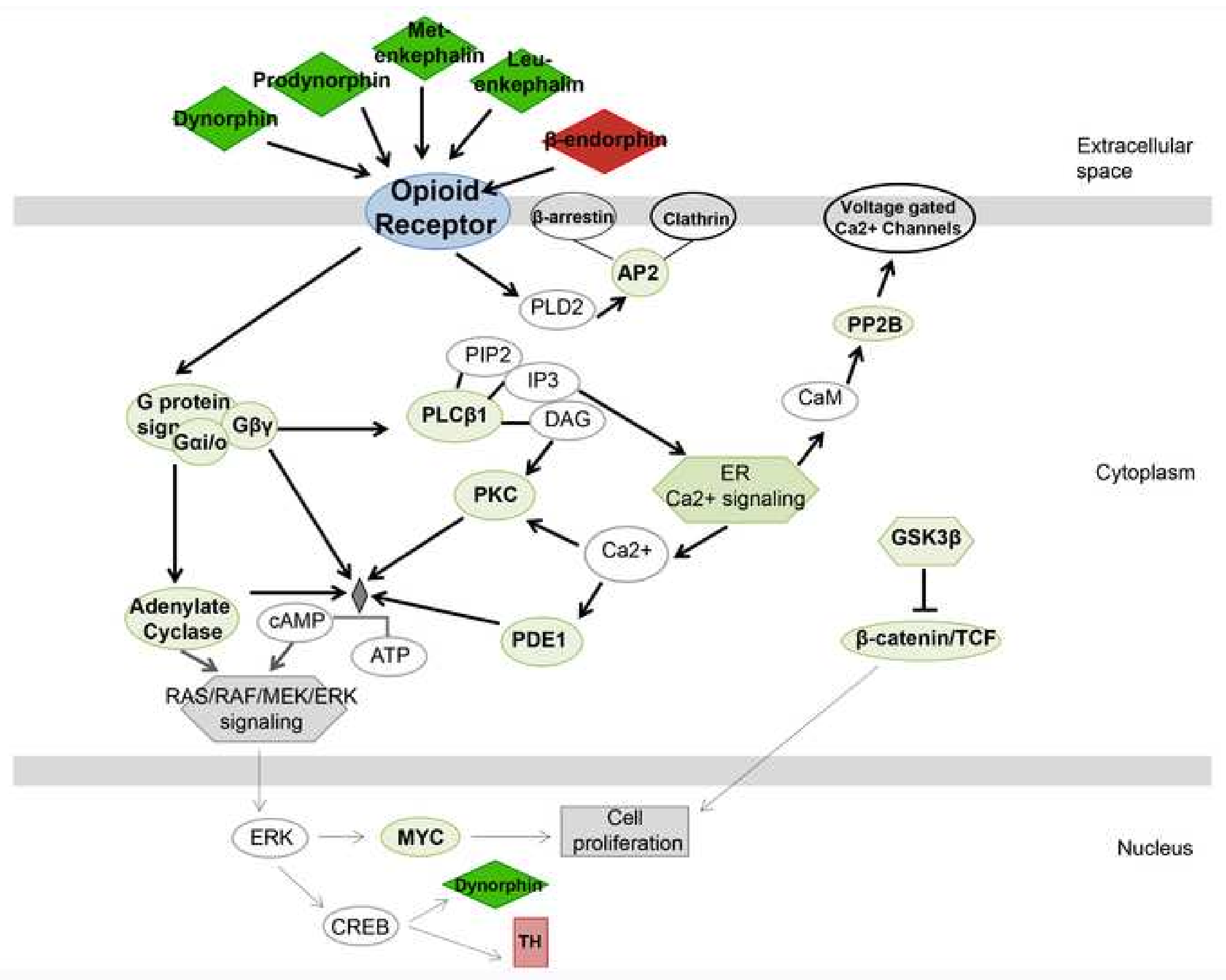



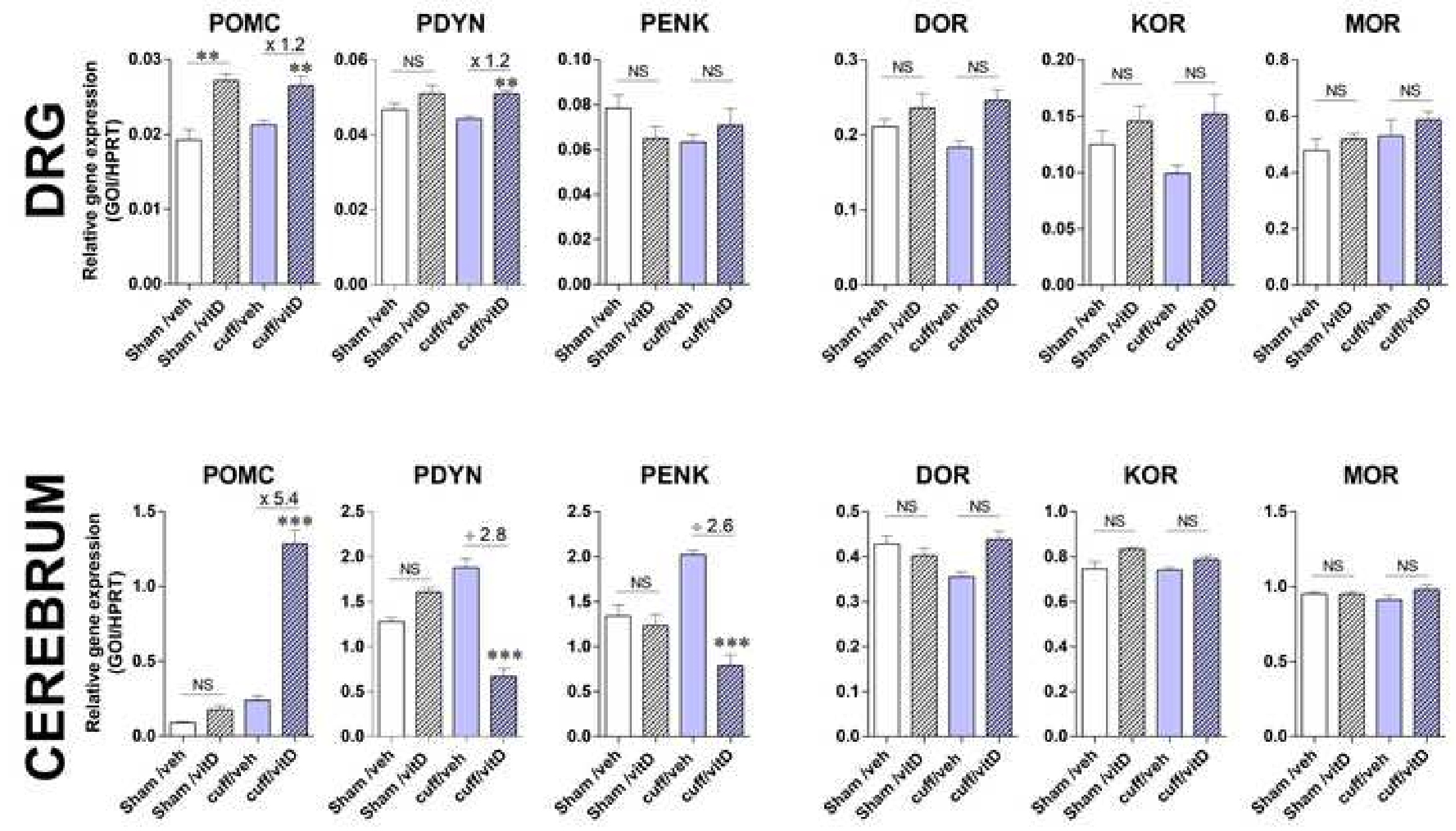

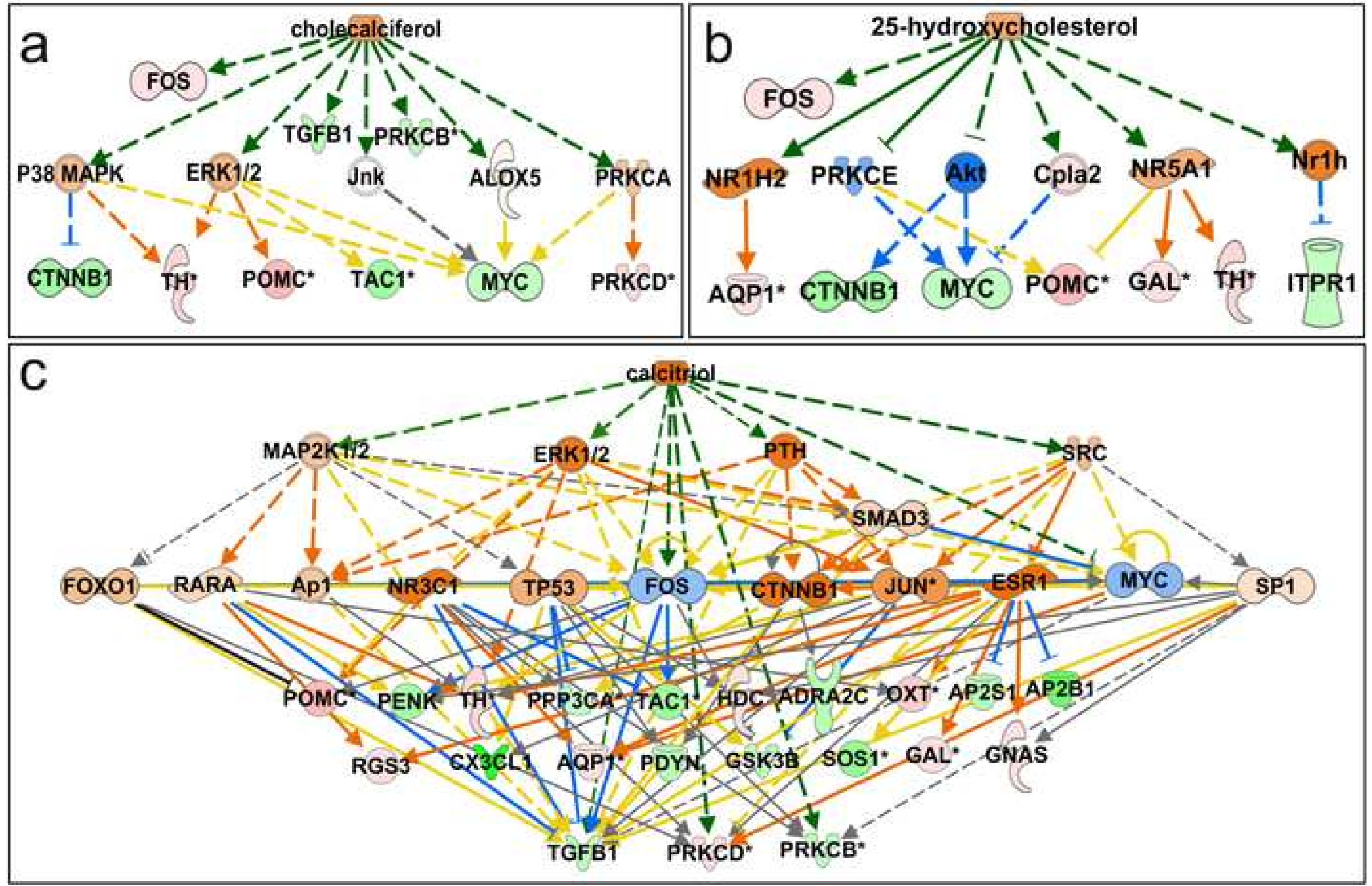
Click here to access/download Supplementary Material Poisbeau et al_Figure S1rev.tif 
Click here to access/download Supplementary Material Poisbeau et al_FigureS2rev.tif 
Click here to access/download Supplementary Material Poisbeau et al_Figure S3.tif 
Click here to access/download Supplementary Material Poisbeau et al_Suppl table 1.tif 
Click here to access/download Supplementary Material Suppl table 2_genes vitD.docx 